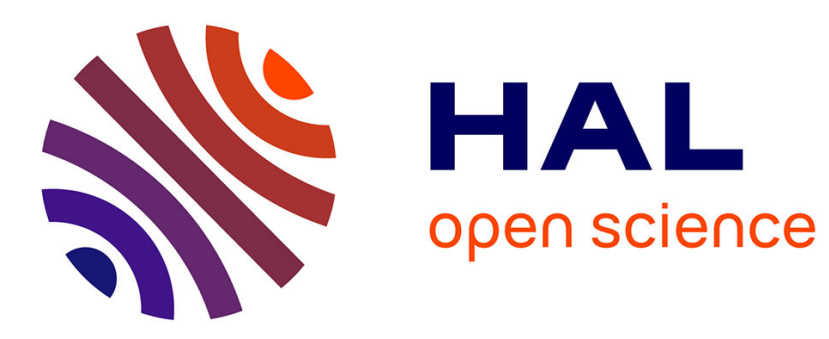

\title{
Role of Proteasome Inhibitors in Relapsed and/or Refractory Multiple Myeloma
}

Xavier Leleu, Thomas G. Martin, Hermann Einsele, Roger M. Lyons, Brian G.M. Durie, Karim S. Iskander, Sikander Ailawadhi

\section{To cite this version:}

Xavier Leleu, Thomas G. Martin, Hermann Einsele, Roger M. Lyons, Brian G.M. Durie, et al.. Role of Proteasome Inhibitors in Relapsed and/or Refractory Multiple Myeloma. Clinical Lymphoma, Myeloma \& Leukemia, 2019, 19, pp.9 - 22. 10.1016/j.clml.2018.08.016 . hal-03484591

\section{HAL Id: hal-03484591 https://hal.science/hal-03484591}

Submitted on 20 Dec 2021

HAL is a multi-disciplinary open access archive for the deposit and dissemination of scientific research documents, whether they are published or not. The documents may come from teaching and research institutions in France or abroad, or from public or private research centers.
L'archive ouverte pluridisciplinaire HAL, est destinée au dépôt et à la diffusion de documents scientifiques de niveau recherche, publiés ou non, émanant des établissements d'enseignement et de recherche français ou étrangers, des laboratoires publics ou privés.

\section{(ㅇ)(1) $\$$}

Distributed under a Creative Commons Attribution - NonCommercial| 4.0 International 


\section{Role of Proteasome Inhibitors in Relapsed and/or Refractory Multiple Myeloma}

2 Xavier Leleu ${ }^{1}$, Thomas G Martin², Hermann Einsele ${ }^{3}$, Roger M Lyons ${ }^{4}$, Brian GM Durie ${ }^{5}$, Karim S Iskander ${ }^{6}$

3 and Sikander Ailawadhi ${ }^{7}$

$4 \quad{ }^{1} \mathrm{CHU}$ la Miletrie and Inserm CIC 1402, Poitiers, France, Xavier.LELEU@chu-poitiers.fr; ${ }^{2}$ University of

5 California, San Francisco, CA, USA, Tom.Martin@ucsf.edu; ${ }^{3}$ University Hospital Würzburg, Würzburg,

6 Germany, Einsele_H@ukw.de; ${ }^{4}$ Texas Oncology and US Oncology Research, San Antonio, TX, USA,

7 Roger.Lyons@USONCOLOGY.COM; ${ }^{5}$ Cedars-Sinai Comprehensive Cancer Center, Los Angeles, CA, USA,

8 bdurie@myeloma.org; ${ }^{6}$ Amgen Inc., Thousand Oaks, CA, USA, iskander@amgen.com; ${ }^{7}$ Mayo Clinic,

9 Jacksonville, FL, USA, Ailawadhi.Sikander@mayo.edu.

Correspondence: Xavier Leleu, CHU la Miletrie and Inserm CIC 1402, Poitiers, France. E-mail:

Xavier.LELEU@chu-poitiers.fr

Running title: Proteasome inhibitors in relapsed multiple myeloma

\section{Competing Interests}

XL reports consulting, honoraria, and membership on an entity's Board of Directors or advisory committees for Janssen, Novartis, BMS, Celgene, Merck, Amgen, Sanofi, Pierre Fabre, and Abbvie; and honoraria and membership and membership on an entity's Board of Directors or advisory committees for Takeda, Incyte, and Gilead. HE reports honoraria, research funding, and advisory participation for Amgen, Celgene, and Janssen; and honoraria and advisory role participation for BMS, Novartis, and Takeda. TGM reports consultancy for Sanofi and receipt of research funding through USCF from Amgen. RML reports no conflicts of interest to disclose. BGMD reports consulting fees from Takeda and Janssen. KSI reports employment and stock ownership with Amgen. SA reports research funding from Pharmacyclics; consultancy and honoraria from Takeda, Amgen, and Novartis; and consultancy for Celgene. 
Proteasome inhibition is an established treatment strategy for patients with multiple myeloma as proteasome inhibitors selectively target and disrupt the protein metabolism of aberrant plasma cells. Since the introduction of the first-in-class proteasome inhibitor bortezomib, the therapeutic landscape for multiple myeloma has shifted with the development of next-generation proteasome inhibitors (carfilzomib and ixazomib) and new classes of agents. Treatment with modern combination therapies has been shown to result in deep responses and improved outcomes, and these potent regimens are increasingly used as frontline therapy. As patients continue to live longer with modern frontline therapy, there will be an increased need for effective regimens after initial treatment failure. Several recent studies have shown that treatment with combination therapy incorporating proteasome inhibitors induces deep and durable responses in patients with relapsed and/or refractory multiple myeloma. In this review, we review pivotal data and discuss the role of proteasome inhibitor-based doublet and triplet regimens for the management of relapsed/refractory multiple myeloma in the era of modern combination therapy. 


\section{INTRODUCTION}

Multiple myeloma is a plasma cell dyscrasia characterized by uncontrolled proliferation and bone marrow infiltration of aberrant plasma cells and the presence of abnormal monoclonal protein secreted by these cells in the serum and/or urine. ${ }^{1}$ It is the second most common hematologic malignancy in the United States (30 280 estimated new cases in 2017) ) $^{1,2}$ and constitutes $0.8 \%$ of all new cancer cases worldwide. $^{3}$

Multiple myeloma is an aggressive and incurable disease for most patients, characterized by periods of remission and relapse. Patients with relapsed multiple myeloma have been defined by Dimopoulos et al as those with active disease who have received at least one prior therapy and are not refractory to the last therapy; patients with relapsed/refractory multiple myeloma are defined as those with disease relapse who have previously achieved at least a minimal response or those with disease progression on salvage therapy or within 60 days of discontinuation of last therapy. ${ }^{4}$ With each relapse, patients face increasingly worse outcomes and each subsequent line of therapy tends to result in a shorter duration of response than previous lines. Each line of therapy is associated with an increased risk of treatmentand disease-related complications. ${ }^{5}$ The poor prognosis also reflects the genomic complexity of relapsed multiple myeloma, with tumors acquiring multiple genetic and epigenetic alterations that promote treatment resistance and refractory disease. ${ }^{1,4}$ The introduction of new classes of drugs, such as proteasome inhibitors, has improved survival outcomes in these difficult-to-treat populations. ${ }^{6-8}$

The ubiquitin-proteasome pathway regulates cellular homeostasis through protein catabolism (proteolysis). ${ }^{9-12}$ Inhibition of proteasome function disrupts several important cellular pathways and affects malignant plasma cells to a greater extent than normal cells. Proteasome inhibition as a treatment strategy for multiple myeloma was clinically validated with the accelerated approval of the first-in-class proteasome inhibitor bortezomib in 2003 for relapsed/refractory multiple myeloma. Since 
this approval, 2 next-generation proteasome inhibitors, carfilzomib and ixazomib, have also been approved for patients with relapsed/refractory multiple myeloma. ${ }^{13}$

With the availability of several distinct proteasome inhibitors and other new drug classes (eg, histone deacetylase inhibitors, monoclonal antibodies) with established efficacy, the potential options for multidrug regimens based on proteasome inhibitors have increased. In addition, the treatment paradigm for multiple myeloma has shifted to a more aggressive approach emphasizing the early use of potent combination therapies to achieve deep responses and prolonged survival. ${ }^{14}$ More than half of patients who are treated with modern multidrug regimens along with transplantation and maintenance achieve a complete response, ${ }^{15}$ which has been associated with improved survival outcomes. ${ }^{16}$ Based on these observations, frontline therapy with 3-drug regimens is currently considered a standard of care. ${ }^{17}$ Importantly, recent data from the SWOG S0777 study showed that treatment with the 3-drug combination of bortezomib, lenalidomide, and dexamethasone significantly improved progression-free survival (PFS) and overall survival (OS) compared with lenalidomide and dexamethasone alone in patients with newly diagnosed multiple myeloma. ${ }^{18}$ Thus, as frontline triplet therapy becomes more established and patients continue to live longer, there will be greater need for potent regimens after initial treatment failure. In a study of Medicare patients with multiple myeloma diagnosed between 2008 and 2011, it was found that among patients who received frontline doublets, 58\% continued doublets as second-line therapy. ${ }^{19}$ Among patients receiving frontline triplets, $26 \%$ continued triplets, $47 \%$ switched to doublets, and $27 \%$ switched to monotherapy as second-line therapy. ${ }^{19}$ These treatment patterns underscore the ongoing need for effective doublet and triplet therapy at first relapse. Modern combination regimens, including those based on proteasome inhibitors, have been found to result in deep responses, even in patients with relapsed/refractory disease..$^{14,20}$

Although not every modern combination regimen includes a proteasome inhibitor, proteasome inhibition is an important treatment strategy for patients with multiple myeloma. Given the essential 
role of proteasome inhibition in multiple myeloma and the availability of several potential treatment options for patients with relapsed/refractory disease, it is important to assess the role of proteasome inhibitors in this setting to aid in the selection of optimal treatment strategies. Here, we review pivotal data and discuss the role of proteasome inhibitor-based doublet and triplet regimens for the management of relapsed/refractory multiple myeloma in the era of modern combination therapy.

\section{DISCUSSION}

\section{The Proteasome and Proteasome Inhibitors}

The proteasome, first observed in 1968 and characterized in the late 1980 's, ${ }^{9-12}$ is a multicatalytic protease complex located in the nucleus and cytoplasm of eukaryotic cells. Each catalytic subunit ( $\beta 1$, $\beta 2, \beta 5)$ of the proteasome is named after an enzyme with similar proteolytic activity as the corresponding subunit: caspase-like, trypsin-like, and chymotrypsin-like, respectively. ${ }^{21}$ The proteasome is a key component of the ubiquitin-proteasome pathway, which is a central platform for recycling proteins involved in important cellular processes including cell cycle progression, DNA repair, and transcription. ${ }^{22}$ The scientists responsible for the discovery of ubiquitin-mediated protein degradation were awarded the Nobel Prize in Chemistry in $2004 .{ }^{23}$ Timely proteolysis through the ubiquitinproteasome pathway is an important regulator of homeostasis in normal cells. ${ }^{22}$ Malignant plasma cells almost always secrete a greater amount of immunoglobulins (ie, proteins) than normal plasma cells and are consequently more dependent on the ubiquitin-proteasome pathway for survival. ${ }^{21}$ Therefore, the proteasome is a rational target for antimyeloma therapies. Preclinical studies have demonstrated that proteasome inhibition results in the build-up of proteins within malignant plasma cells leading to activation of the unfolded protein stress response and decreased NF-KB activity, both of which induce apoptosis. $^{21}$ 
Three proteasome inhibitors have been approved for the treatment of patients with multiple myeloma: bortezomib, carfilzomib, and ixazomib. Structurally, bortezomib is a dipeptide boranate. ${ }^{21}$ Functionally, it is a slowly reversible inhibitor targeting primarily the $\beta 5$ subunit of the proteasome, with less potent inhibition effects on the $\beta 1$ and $\beta 2$ subunits. ${ }^{21}$ Since the introduction of bortezomib, 2 new proteasome inhibitors have entered the clinic for patients with relapsed/refractory multiple myeloma, carfilzomib (first approved in 2012) and ixazomib (first approved in 2015). Carfilzomib, bortezomib, and ixazomib have unique structural and mechanistic properties, resulting in differential proteasome inhibition profiles. Carfilzomib, a tetrapeptide epoxyketone, selectively targets and irreversibly inhibits the proteasome. Compared with bortezomib, carfilzomib has greater selectivity for the $\beta 5$ subunit ${ }^{21}$ of the proteasome and less off-target activity against nonproteasomal proteases. ${ }^{24}$ In patients with relapsed or refractory multiple myeloma, carfilzomib has been shown to induce deeper and more sustained proteasome inhibition compared with bortezomib. ${ }^{25}$ Ixazomib is structurally similar to bortezomib and is a citrate ester of boronic acid. ${ }^{13}$ After aqueous exposure, ixazomib hydrolyzes to the free boric acid MLN2238, which is the pharmacologically active metabolite. ${ }^{13}$ Ixazomib reversibly inhibits the proteasome with selectivity for the $\beta 5$ subunit. Ixazomib is orally bioavailable and has a shorter 205 proteasome disassociation half-life than bortezomib. ${ }^{26}$ In preclinical studies, ixazomib demonstrated more favorable pharmacokinetic, pharmacodynamic, and antitumor activity profiles compared with bortezomib. $^{26}$

Activity of Approved Proteasome Inhibitor-Based Combination Therapies in Relapsed/Refractory Multiple Myeloma

To date, a total of 7 proteasome inhibitor-based combination therapies have been approved for the treatment of patients with relapsed/refractory multiple myeloma (doublet, $n=3$; triplet, $n=4$ ). The approved doublets are bortezomib plus dexamethasone, bortezomib plus pegylated doxorubicin, and carfilzomib plus dexamethasone. The approved triplets are bortezomib plus panobinostat and 
dexamethasone, bortezomib plus daratumumab and dexamethasone, carfilzomib plus lenalidomide and dexamethasone, and ixazomib plus lenalidomide and dexamethasone. Pivotal data supporting the approval of these therapies are summarized in Tables 1 and 2. Results from these pivotal studies and studies supporting other combination therapies recommended by the National Comprehensive Care Network are described below. The current National Comprehensive Care Network Guidelines evaluate treatments with categories of evidence and consensus (eg, category 1: based upon high-level evidence and there is uniform consensus the intervention is appropriate; category 2A: based upon lower-level evidence and there is uniform consensus the intervention is appropriate) and categories of preference (eg, preferred intervention: based on superior evidence; other recommended intervention: interventions may be somewhat less effective, more toxic, or based on less mature data). ${ }^{17}$ These categories of evidence and consensus from the National Comprehensive Care Network guidelines are included in the descriptions of the proteasome inhibitor-based therapies in this review. All proteasome inhibitor-based doublets recommended by the National Comprehensive Care Network guidelines were included in the review. Because there are a large number of recommended proteasome inhibitor-based triplets in these guidelines, only triplets based on a proteasome inhibitor plus an immunomodulatory agent or monoclonal antibody were included, as these were deemed to be the most clinically relevant based on the authors' judgment.

Approved Bortezomib-Based Regimens

\section{$\underline{\text { Doublets }}$}

Bortezomib plus dexamethasone has been a standard of care in relapsed/refractory multiple myeloma and was approved in the United States in 2014 when used as re-treatment (see Re-treatment with Proteasome Inhibitors) and in the European Union in 2014 for patients with progressive multiple myeloma who have received at least one prior therapy. The broader European Union approval was 
based on a retrospective matched-pairs analysis of the MMY-2045, APEX, and DOXIL-MMY-3001 clinical trials. The analysis demonstrated improved overall response rate $(75 \%$ vs. $41 \%$; odds ratio, 3.467 ; $P<0.001$ ), time to progression (median, 13.6 vs. 7.0 months; hazard ratio $[\mathrm{HR}], 0.394 ; P=0.003$ ), and PFS (median, 11.9 vs. 6.4 months, HR, 0.595; $P=0.051$ ) after second-line treatment with bortezomib and dexamethasone versus bortezomib alone. ${ }^{39}$ The National Comprehensive Care Network considers bortezomib plus dexamethasone a treatment option under "other recommended regimens" (category 1; not preferred) for patients with relapsed/refractory multiple myeloma. ${ }^{17}$

Bortezomib plus liposomal doxorubicin was approved in 2007 for the treatment of patients with relapsed or refractory multiple myeloma who have not previously received bortezomib and have received at least one prior therapy. This approval was based on the DOXIL-MMY-3001 study, which was a randomized, phase 3 trial comparing bortezomib plus liposomal doxorubicin with bortezomib monotherapy in patients with relapsed or refractory multiple myeloma. At the interim analysis, time to progression was longer for combination treatment compared with monotherapy (median, 9.3 vs. 6.5 months; HR, 1.82 [monotherapy vs. combination]; $P<0.0001) .{ }^{27}$ The results from the final OS analysis of this study showed that OS was similar between the treatment arms (median, 33.0 vs. 30.8 months; HR, 1.05; $P=0.61$ ). ${ }^{28}$ The National Comprehensive Care Network considers bortezomib plus doxorubicin (with dexamethasone) a category 1 option (not preferred) for patients with relapsed/refractory multiple myeloma. ${ }^{17}$

\section{$\underline{\text { Triplets }}$}

Bortezomib has been evaluated as part of triplets combining a proteasome inhibitor with new classes of drugs, as demonstrated in the CASTOR and PANORAMA1 studies. The randomized, phase 3 CASTOR study showed that treatment with daratumumab in combination with bortezomib and dexamethasone resulted in significantly longer PFS compared with bortezomib and dexamethasone alone (median, 16.7 
vs. 7.1 months; HR, 0.31; $P<0.0001) .{ }^{38}$ Based on results from the CASTOR trial, this combination was approved in 2016 for the treatment of patients with multiple myeloma who have received at least one prior therapy. This combination is also considered a preferred regimen (category 1) for the treatment of patients with relapsed/refractory multiple myeloma. ${ }^{17}$

The panobinostat plus bortezomib and dexamethasone regimen was approved in 2015 for patients with multiple myeloma who have received at least 2 prior regimens, including bortezomib and an immunomodulatory drug. The pivotal trial supporting this approval was PANORAMA-1, which evaluated panobinostat or placebo plus bortezomib and dexamethasone in patients with relapsed or relapsed/refractory multiple myeloma. The primary analysis of this trial demonstrated that treatment with panobinostat plus bortezomib and dexamethasone resulted in significantly longer PFS compared with placebo plus bortezomib and dexamethasone (median, 11.99 vs. 8.08 months; HR, 0.63; $P<0.0001) . .^{30}$ The final OS analysis for this trial showed a trend toward OS benefit for panobinostat over placebo, but the difference was not found to be statistically significant (median, 40.3 vs. 35.8 months; HR, 0.94; $P=0.54) .{ }^{31}$ The National Comprehensive Care Network has included this combination as a category 1 option for patients with at least 2 prior therapies, including an immunomodulatory drug and bortezomib. ${ }^{17}$

Approved Carfilzomib-Based Regimens

\section{$\underline{\text { Doublets }}$}

In a head-to-head study of 2 proteasome inhibitors (carfilzomib vs. bortezomib), the randomized, phase 3 ENDEAVOR trial compared carfilzomib $\left(56 \mathrm{mg} / \mathrm{m}^{2}\right.$ infused over 30 minutes) and dexamethasone with bortezomib and dexamethasone in patients with relapsed or refractory multiple myeloma ( 1 to 3 prior lines of therapy). This carfilzomib regimen was based on results from a phase 1 study, which established the maximum tolerated dose of carfilzomib to be $56 \mathrm{mg} / \mathrm{m}^{2}$ when administered as a 30-minute 
infusion. ${ }^{40}$ The first interim analysis of ENDEAVOR showed that there was a statistically significant increase in PFS for the carfilzomib group compared with the bortezomib group (median, 18.7 vs. 9.4 months; HR, $0.53, P<0.0001) .{ }^{32}$ The second interim analysis of ENDEAVOR showed that carfilzomib also provided a significant and clinically meaningful OS improvement compared with bortezomib, prolonging median OS by 7.6 months ( 47.6 vs. 40.0 months; HR, $0.79 ; 1$-sided $P=0.010$ ). ${ }^{36}$ Use of bisphosphonates was balanced between treatment arms and did not confound the OS analysis. ${ }^{41}$ Notably, ENDEAVOR is the first and currently the only phase 3 study to demonstrate a significant OS advantage in the relapsed or refractory multiple myeloma setting in a head-to-head comparison of 2 different proteasome inhibitors. ${ }^{36}$

The results of the ENDEAVOR study established the combination of carfilzomib with dexamethasone as a new treatment option for patients with relapsed or refractory multiple myeloma who are being considered for doublet therapy. ${ }^{36}$ The carfilzomib $\left(56 \mathrm{mg} / \mathrm{m}^{2}\right)$ and dexamethasone combination was approved in 2016 for the treatment of patients with relapsed or refractory multiple myeloma (with 1 to 3 prior lines of therapy), and this combination is the only doublet that is recognized as a preferred treatment option (category 1) for previously treated multiple myeloma by the National Comprehensive Care Network. ${ }^{17}$

\section{$\underline{\text { Triplets }}$}

Results from the interim analysis of the randomized, phase 3 ASPIRE study showed that treatment with carfilzomib (27 mg/m² infused over 10 minutes), lenalidomide, and dexamethasone significantly improved PFS compared with lenalidomide and dexamethasone alone (median, 26.3 vs. 17.6 months; $\mathrm{HR}, 0.69 ; P=0.0001$ ) in patients with relapsed or refractory multiple myeloma ( 1 to 3 prior lines of therapy). The median PFS duration of 26 months in the carfilzomib arm was noted to be the longest observed to date in the relapsed setting. ${ }^{20}$ In the ASPIRE regimen, carfilzomib was given for 18 cycles 
and then patients continued on lenalidomide and dexamethasone alone, similar to the control arm. The current standard of care is to use antimyeloma therapies until disease progression, which is the case for the active arms of other phase 3 trials in relapsed/refractory multiple myeloma reviewed here. A posthoc analysis of ASPIRE showed that the HR for PFS at 18 months was $0.58 .{ }^{42}$ Recently, results from a prespecified final analysis of OS in ASPIRE showed that carfilzomib plus lenalidomide and dexamethasone reduced the risk of death compared with lenalidomide and dexamethasone, prolonging median OS by 7.9 months ( 48.3 vs. 40.4 months; $\mathrm{HR}, 0.79 ; 95 \% \mathrm{Cl}, 0.67-0.95) .{ }^{37}$ Notably, this is the first and currently the only study in patients with relapsed or refractory multiple myeloma to demonstrate an OS advantage for a triplet regimen against lenalidomide and dexamethasone.

Based on results from the ASPIRE study, the combination of carfilzomib with lenalidomide and dexamethasone was approved in 2015 for the treatment of patients with relapsed or refractory multiple myeloma (1 to 3 prior lines of therapy in the United States and 1 or more prior line in the European Union). This regimen is also considered a category 1 preferred treatment option for patients with previously treated multiple myeloma by the National Comprehensive Care Network. ${ }^{17}$

\section{Approved Ixazomib-Based Regimens}

\section{$\underline{\text { Doublets }}$}

Ixazomib is currently not approved by the US Food and Drug Administration to be used as part of a doublet for the treatment of relapsed and/or refractory multiple myeloma.

\section{$\underline{\text { Triplets }}$}

Interim results from the randomized, phase 3 TOURMALINE-MM1 study demonstrated that the addition of ixazomib (versus placebo) to lenalidomide and dexamethasone significantly prolonged PFS in patients with relapsed and/or refractory multiple myeloma (median 20.6 vs. 14.7 months; HR $0.74 ; P=0.01$ ). ${ }^{35}$ These data supported the approval (2015) of ixazomib plus lenalidomide and dexamethasone for the 
treatment of patients with multiple myeloma who have received at least one prior therapy. In addition, this regimen is a category 1 preferred treatment option for patients with previously treated multiple myeloma. ${ }^{17}$ Notably, this regimen is the only approved all-oral triplet based on a proteasome inhibitor.

Longer follow-up results from TOURMALINE-MM1 demonstrated a smaller improvement in PFS compared with the interim results (median, 20.0 vs. 15.9 months; $P=0.05) .{ }^{43}$

\section{Activity of Other Proteasome Inhibitor-Based Combination Therapies in Relapsed/Refractory Multiple}

\section{Myeloma}

Several other proteasome-inhibitor based combination regimens are recommended by clinical guidelines, but have not yet been approved by regulatory agencies. This section summarizes the data supporting treatment recommendations from the National Comprehensive Care Network, with a focus on doublets and triplets containing a proteasome inhibitor and dexamethasone with either an immunomodulatory drug or a monoclonal antibody.

\section{Doublets}

The combination of once-weekly carfilzomib plus dexamethasone for patients with relapsed or refractory multiple myeloma was evaluated in the phase $1 / 2$ CHAMPION-1 study. The phase 1 portion of this trial established the maximum tolerated dose of carfilzomib administered once weekly (30-minute infusion) as $70 \mathrm{mg} / \mathrm{m}^{2} .{ }^{44}$ Among patients treated at this dose in the phase 1 and 2 portions of the study $(n=104)$, the overall response rate was $77 \%$ and median PFS was 12.6 months, demonstrating the activity of this regimen. ${ }^{44}$ Once-weekly administration of carfilzomib may be more convenient for patients compared with twice-weekly administration. The carfilzomib regimen used in CHAMPION-1 is included in the National Comprehensive Care Network guidelines as a recommended regimen (category 2A). ${ }^{17}$ This regimen is being investigated in the phase 3 ARROW study (NCT02412878), which compares once-weekly carfilzomib $\left(70 \mathrm{mg} / \mathrm{m}^{2}\right)$ versus twice-weekly carfilzomib $\left(27 \mathrm{mg} / \mathrm{m}^{2}\right)$. At the interim analysis, 
this trial met its primary endpoint. Patients who received the once-weekly carfilzomib had significantly longer PFS compared with those who received the twice-weekly carfilzomib regimen (median, 11.2 vs. 7.6 months; $\mathrm{HR}, 0.69 ; 95 \% \mathrm{Cl}, 0.54-0.88) .{ }^{45}$

Ixazomib is currently not approved in any doublet regimen, but the combination of ixazomib and dexamethasone has shown promising activity in 2 phase 2 studies. In 1 study $(N=33)$, patients with relapsed multiple myeloma with limited prior exposure to bortezomib received weekly ixazomib with dexamethasone added for suboptimal responses (lack of a minor response by cycle 2, partial response by cycle 4 , or disease progression at any time). Dexamethasone was added for 22 (67\%) patients, 4 of whom achieved a partial response or better after suboptimal response. With or without the addition of dexamethasone, the overall response rate was 34\%, and the median event-free survival was 11.5 months. ${ }^{46}$ In the other study $(N=70)$, patients with relapsed multiple myeloma (who were proteasome inhibitor-naïve or received fewer than 6 cycles of therapy with bortezomib and had a partial response or better with no progression at the time of discontinuation) were randomized to receive ixazomib 4 or 5.5 $\mathrm{mg}$ in combination with dexamethasone. Overall response rates were $31 \%$ in the $4 \mathrm{mg}$ arm and $51 \%$ in the $5.5 \mathrm{mg}$ arm. ${ }^{47}$ Median event-free survival was similar for both arms ( 8.4 and 8.2 months, respectively). Patients receiving the $5.5-\mathrm{mg}$ dose had higher rates of grade $\geq 3$ adverse events considered possibly related to treatment (54\% vs. $21 \%$ ) and adverse events requiring dose reductions (43\% vs. $17 \%)$ compared with patients receiving the 4-mg dose. Based on these data, the ixazomib plus dexamethasone regimen is recognized as a category $2 \mathrm{~A}$ treatment option for patients with relapsed/refractory multiple myeloma (at least one prior therapy) by the National Comprehensive Care Network. ${ }^{17}$

In addition to proteasome inhibitor-dexamethasone doublet regimens, the pairing of a proteasome inhibitor with a histone deacetylase inhibitor has also been evaluated. ${ }^{48}$ In a phase $1 / 2$ study of carfilzomib plus panobinostat $(N=42)$, the overall response rate was $67 \%$ and median PFS was 7.7 
months in patients with relapsed/refractory multiple myeloma. ${ }^{49}$ Based on this promising phase $1 / 2$ data, carfilzomib plus panobinostat is a recommended treatment option (category $2 \mathrm{~A}$ ) for patients with previously treated multiple myeloma. ${ }^{17}$

\section{Triplets Containing a Proteasome Inhibitor and an Immunomodulatory Drug}

Although not yet approved by regulatory agencies, the combination of bortezomib, lenalidomide, and dexamethasone is considered a preferred regimen (category 1) for the treatment of patients with relapsed/refractory multiple myeloma by the National Comprehensive Care Network. ${ }^{17}$ This recommendation is based on results from a phase 2 study of 64 patients with relapsed or relapsed/refractory multiple myeloma. In this study, the overall response rate was $64 \%$, median PFS was 9.5 months, and median OS was 30 months. ${ }^{50}$ Notably, the SWOG S0777 study showed that treatment with this triplet improved PFS and OS compared with lenalidomide and dexamethasone in patients with newly diagnosed multiple myeloma. ${ }^{18}$

Combination regimens consisting of pomalidomide and dexamethasone with bortezomib, carfilzomib, or ixazomib are considered recommended therapeutic options (category $2 \mathrm{~A}$ ) by the National

Comprehensive Care Network for patients who have received at least 2 prior therapies, including an immunomodulatory drug and a proteasome inhibitor (specifically bortezomib for the bortezomib- and carfilzomib-based triplets), and have demonstrated disease progression on or within 60 days of completion of the last therapy. ${ }^{17}$ Phase 1 studies have demonstrated promising activity for bortezomib with pomalidomide and dexamethasone; ${ }^{17}$ the randomized phase 3 OPTIMISMM trial (NCT01734928) recently showed that bortezomib with pomalidomide and dexamethasone improved PFS compared with bortezomib and dexamethasone alone in patients with relapsed or refractory multiple myeloma. ${ }^{51}$ In phase 1 and 2 studies, treatment with carfilzomib plus pomalidomide and dexamethasone was found to be highly active in both heavily pretreated patients with relapsed or refractory multiple myeloma 
(median of 6 prior regimens; $N=72$ ), with an overall response rate of $64 \%,{ }^{52}$ and less pretreated, proteasome inhibitor naïve/sensitive patients $(n=64)$, with an overall response rate of $84 \% .{ }^{53}$ In phase $1 / 2$ studies, ixazomib plus pomalidomide and dexamethasone has shown early promising activity in patients with double-refractory disease (partial response or better in 8 of 13 patients) ${ }^{54}$ and in patients with relapsed/refractory multiple myeloma who received at least one prior therapy $(n=25$, overall response rate of $48 \%) .^{55}$

\section{Triplets Containing a Proteasome Inhibitor and a Monoclonal Antibody}

A randomized, phase 2 study compared elotuzumab plus bortezomib and dexamethasone versus bortezomib and dexamethasone in patients with relapsed/refractory multiple myeloma $(N=152)$. At the time of the primary analysis, the addition of elotuzumab to bortezomib and dexamethasone resulted in statistically significantly longer PFS compared with bortezomib and dexamethasone alone (median, 9.7 vs. 6.9 months; HR, 0.72; $P=0.09$ [statistical significance threshold of 2 -sided $P \leq 0.3$ was used]). ${ }^{56}$ In an updated analysis, the 2-year PFS rates were $18 \%$ for bortezomib plus elotuzumab and dexamethasone and $11 \%$ for bortezomib and dexamethasone. ${ }^{56}$ This triplet combination is considered a recommended regimen (category $2 \mathrm{~A}$; not preferred) for patients with relapsed/refractory multiple myeloma who have received at least one therapy by the National Comprehensive Care Network. ${ }^{17}$

\section{Activity of Proteasome Inhibitor-Based Regimens at First Relapse}

The first relapse is a critical juncture on the myeloma disease continuum. Each subsequent relapse is associated with increased genomic complexity and drug resistance, resulting in increasingly shorter response durations. ${ }^{57,58}$ Furthermore, data suggest that achievement of deep responses at first relapse versus subsequent relapses is more strongly associated with improved survival outcomes. ${ }^{59}$ Thus, early treatment with highly effective therapy at first relapse, when the disease is still at a sensitive stage, is critical for maximizing OS for patients with relapsed/refractory multiple myeloma. ${ }^{57,60}$ Consistent data 
341 from pivotal trials show that proteasome inhibitor-based combination therapies are highly effective 342 treatment options for first relapse (Table 3).

\section{Doublets}

344 The matched-pairs analysis, described previously, compared bortezomib and dexamethasone with

345 single-agent bortezomib. This analysis showed that bortezomib and dexamethasone resulted in greater

346 response and delayed disease progression compared with bortezomib monotherapy when used as

347 second-line treatment. ${ }^{39}$

348 A secondary analysis of the ENDEAVOR study established the benefit of carfilzomib and dexamethasone

349 when used at first relapse, and demonstrated that it is more effective than bortezomib and

350 dexamethasone in this setting. Results from this analysis showed that in the subgroup of patients who

351 had received 1 prior line of therapy, there was a clinically meaningful improvement in PFS for patients

352 treated with carfilzomib plus dexamethasone versus bortezomib and dexamethasone (median, 22.2 vs.

35310.1 months; HR, 0.447; $P<0.0001) .{ }^{61}$ Additionally, the final OS analysis of ENDEAVOR showed that

354 patients at first relapse had a 17\% lower risk of death if treated with carfilzomib plus dexamethasone

355 versus bortezomib plus dexamethasone (median OS was not estimable in either arm). ${ }^{62}$

356 Triplets

357 The ASPIRE study established the benefit of adding carfilzomib to the immunomodulatory backbone of

358 lenalidomide and dexamethasone for the treatment of patients at first relapse. A secondary analysis of

359 the ASPIRE study demonstrated that the addition of carfilzomib to lenalidomide and dexamethasone led

360 to a 12-month improvement in median PFS compared with lenalidomide and dexamethasone alone

361 (29.6 vs. 17.6 months; HR, 0.71; $P=0.0118$ ) in patients with 1 prior line of therapy.$^{64}$ Importantly, the

362 final analysis of OS in ASPIRE showed that the OS benefit for the carfilzomib group compared with the 
control group was most pronounced at first relapse, with an 11-month prolongation of median OS (47.3 vs. 35.9 months; $H R, 0.81) .{ }^{37}$

A subgroup analysis of the TOURMALINE-MM1 study demonstrated a trend for improvement in PFS with ixazomib, lenalidomide, and dexamethasone compared with lenalidomide and dexamethasone alone for patients at first relapse (median, 20.6 vs. 16.6 months; $\mathrm{HR}, 0.88 ; 95 \% \mathrm{Cl}, 0.65-1.20) .{ }^{65}$ However, the magnitude of benefit $(H R, 0.88)$ appeared to be lower than that in the overall population $(H R, 0.74)$. It was noted that patients with 1 prior therapy without transplant had greater benefit with ixazomib, lenalidomide, and dexamethasone than patients with 1 prior therapy and transplant (HR 1.232 vs. 0.604) and further investigation into this effect is ongoing. ${ }^{65}$

Another pivotal study demonstrated the benefit of adding a novel agent to the proteasome inhibitor backbone of bortezomib and dexamethasone for patients at first relapse. In a subgroup analysis of CASTOR, it was found that the addition of daratumumab to bortezomib and dexamethasone led to significantly improved PFS for patients with 1 prior line of therapy (median, not reached vs. 7.9 months; HR, 0.19; $P<0.0001) \cdot{ }^{38}$

\section{Re-treatment with Proteasome Inhibitors in Proteasome Inhibitor-Sensitive Patients}

The choice of salvage therapy at relapse is an important decision that depends on several factors, including the type of previous treatment and duration of response to previous treatment. As bortezomib-based regimens are among the most commonly used frontline therapies, ${ }^{66}$ it is important that treatments used at relapse retain efficacy and tolerability in patients with previous bortezomib exposure. Several proteasome inhibitor-based doublets and triplets have demonstrated activity in patients with prior bortezomib exposure.

\section{Doublets}


Guidelines from the National Comprehensive Care Network state that if relapse occurs more than 6 months after treatment completion, re-treatment with the same therapy may be considered. ${ }^{17}$ In concordance with these guidelines, the phase 2 RETRIEVE trial $(n=126)$ showed that re-treatment with bortezomib (with or without dexamethasone) was effective (overall response rate of $40 \%$ ) in patients with multiple myeloma who had achieved a partial response or better upon completion of prior bortezomib therapy and relapsed more than 6 months after prior bortezomib therapy. ${ }^{29}$ These data supported approval of bortezomib re-treatment (as a single agent or with dexamethasone) for patients with relapsed multiple myeloma.

The ENDEAVOR study included a large group of patients $(n=502)$ who were previously exposed to bortezomib but were not bortezomib refractory (similar to the RETRIEVE population), which allowed for a robust comparison of carfilzomib and dexamethasone versus bortezomib and dexamethasone among patients with prior bortezomib exposure (Table 4). Median PFS was 7.5 months longer in the carfilzomib group compared with the bortezomib group among patients with previous bortezomib exposure (median, 15.6 vs. 8.1 months; HR, 0.56; P<0.0001). ${ }^{32,61}$ Treatment with carfilzomib also extended OS by 14.8 months versus re-treatment with bortezomib in this subgroup (median, 47.6 vs. 32.8 months; HR, 0.84; 95\% Cl, 0.65-1.08). ${ }^{62}$ Although bortezomib re-treatment has been a common therapeutic strategy, ${ }^{66}$ these head-to-head results suggest that treatment with carfilzomib at relapse is more effective (complete response rates, PFS, and OS) than re-treatment with bortezomib for patients with prior bortezomib exposure.

\section{Triplets}

Triplet regimens that combine proteasome inhibitors with a lenalidomide-dexamethasone backbone have also improved outcomes compared with lenalidomide-dexamethasone alone in patients with previous bortezomib exposure. In the ASPIRE study, the addition of carfilzomib to lenalidomide and 
dexamethasone resulted in an approximate 8-month improvement in median PFS in bortezomibexposed patients (median, 24.4 vs. 16.6 months; HR, 0.699) and for patients treated at first relapse after bortezomib-containing therapy, carfilzomib plus lenalidomide and dexamethasone resulted in 13.4 months of improvement (median, 29.3 vs. 15.9 months; HR, 0.577). ${ }^{64,67}$ Further, the addition of carfilzomib to lenalidomide and dexamethasone prolonged median OS by 12 months (median, 45.9 vs. 33.9 months; $\mathrm{HR}, 0.82 ; 95 \% \mathrm{Cl}, 0.56-1.19)$ among patients treated at first relapse after prior bortezomib. $^{37}$

A subgroup analysis of the TOURMALINE-MM1 study showed a consistent PFS benefit for ixazomib, lenalidomide, and dexamethasone versus lenalidomide and dexamethasone, regardless of prior bortezomib exposure (bortezomib-exposed: median, 18.5 vs. 13.6 months; HR, 0.746; bortezomib-naïve: median, not estimable vs. 15.9 months; HR, 0.747)..$^{65}$

Results from subgroup analyses of the CASTOR and PANORAMA-1 trials suggest that treatment with potent triplet combinations based on the bortezomib-dexamethasone backbone may be more effective than treatment with this backbone alone in patients with prior bortezomib exposure. In the CASTOR study, PFS was improved with daratumumab plus bortezomib and dexamethasone compared with bortezomib and dexamethasone alone, regardless of prior bortezomib exposure (bortezomib-exposed: median, 12.3 vs. 6.7 months; HR, 0.46). ${ }^{33}$ Among prior treatment subgroups examined in the PANORAMA-1 study (group 1: prior immunomodulatory drug; group 2: prior bortezomib and immunomodulatory drug; group 3: 2 or more prior regimens including bortezomib and an immunomodulatory drug), the PFS benefit for panobinostat plus bortezomib and dexamethasone versus bortezomib and dexamethasone alone was most pronounced in patients who had received at least 2 prior therapies, including bortezomib and an immunomodulatory drug, with a 7.8-month prolongation in median PFS (median, 12.5 vs. 4.7 months; HR, 0.47). ${ }^{34}$ 


\section{Re-treatment with Proteasome Inhibitors in Proteasome Inhibitor-Refractory Patients}

As bortezomib is a commonly used frontline antimyeloma agent, there is a need for therapies that can recapture responses in patients who become bortezomib-refractory. Proteasome inhibitor-based combinations have demonstrated activity in this setting (Table 5), and several general approaches have been used. The first is the addition of a novel agent with a unique mechanism of action to a bortezomibbased backbone. This was tested in the phase 2 PANORAMA trial where the histone deacetylase inhibitor panobinostat was added to bortezomib and dexamethasone. Treatment with this combination resulted in an overall response rate of $35 \%$ in bortezomib-refractory patients $(n=55) .{ }^{50}$ More recent studies have evaluated the addition of venetoclax (a BCL-2 inhibitor) or selinexor (a selective exportin 1 inhibitor) to bortezomib and dexamethasone with promising activity; however, these combinations are not yet endorsed by regulatory agencies or the National Comprehensive Care Network. Another approach for proteasome inhibitor-based treatment of bortezomib-refractory patients is the use of a different proteasome inhibitor, ie carfilzomib or ixazomib. Preclinically, carfilzomib and ixazomib are able to overcome bortezomib resistance in multiple myeloma cell lines and patient samples. ${ }^{71,72}$ Building on this preclinical rationale, several carfilzomib or ixazomib-based combinations have demonstrated activity in bortezomib-refractory patients (Table 5). Notably, ASPIRE is the only pivotal phase 3 trial of proteasome inhibitor-based combination therapy to have reported efficacy data for bortezomibrefractory patients. Among these patients in ASPIRE, median PFS was extended 3 months with the addition of carfilzomib to lenalidomide and dexamethasone (22.3 vs. 19.4 months; HR, 0.80), and the HR for OS (0.73) also favored the carfilzomib group. ${ }^{37,64}$

The addition of novel agents (eg, panobinostat, venetoclax, or selinexor) to a carfilzomib-based regimen has also been investigated recently, and has generally shown promising activity in patients refractory to a proteasome inhibitor. With the exception of carfilzomib plus panobinostat, regimens based on this approach have not yet been endorsed by the National Comprehensive Care Network. 


\section{Safety of Proteasome Inhibitor-Based Combination Therapies in Relapsed/Refractory Multiple}

\section{Myeloma}

Bortezomib, carfilzomib, and ixazomib each have their own unique safety profiles, which reflects their distinct structural and mechanistic properties. In the ENDEAVOR study, rates of grade $\geq 3$ adverse events and serious adverse events were slightly more common with carfilzomib versus bortezomib. Grade $\geq 3$ adverse events that were more common ( $\geq 2 \%$ ) with carfilzomib were anemia, hypertension, dyspnea, decreased lymphocyte count, pyrexia, and cardiac failure whereas those that were more common in the bortezomib group were diarrhea and peripheral neuropathy. ${ }^{36}$

The safety profiles of bortezomib and carfilzomib are affected by the route of administration and/or dosing schedule used. Subcutaneous administration has been shown to result in a lower rate of peripheral neuropathy compared with intravenous bortezomib administration. ${ }^{73}$ For carfilzomib, a longer infusion time (ie, 30 vs. 10 minutes) permits safe administration of higher doses of carfilzomib compared with the originally approved dose of $27 \mathrm{mg} / \mathrm{m}^{2} \cdot{ }^{32,44}$ The CHAMPION-1 study showed that once-weekly administration of carfilzomib $\left(70 \mathrm{mg} / \mathrm{m}^{2} ; 30-\right.$ minute infusion) in combination with dexamethasone was generally well tolerated in patients with relapsed or refractory multiple myeloma, with only $12 \%$ of patients discontinuing treatment due to adverse events. ${ }^{44}$

In randomized studies comparing a triplet versus a doublet, adverse event rates tended to be slightly higher in the triplet arm than in the doublet arm, as expected (Table 6). In the PANORAMA-1 study, the addition of panobinostat to bortezomib and dexamethasone was associated with an increased incidence of grade 3 or 4 thrombocytopenia, Iymphopenia, neutropenia, diarrhea, and asthenia or fatigue. ${ }^{30}$ In the ASPIRE study, the addition of carfilzomib to lenalidomide and dexamethasone was associated with an increased incidence of diarrhea, cough, fever, and hypertension. ${ }^{20}$ In the TOURMALINE-MM1 study, the addition of ixazomib to lenalidomide and dexamethasone was associated with an increased incidence of 
thrombocytopenia, rash, gastrointestinal events, and peripheral neuropathy. ${ }^{35}$ In the CASTOR study, the addition of daratumumab to bortezomib and dexamethasone led to an increased incidence of thrombocytopenia and infusion-related reactions. ${ }^{33}$

\section{Factors to Consider When Selecting Proteasome Inhibitor Therapy}

Several disease-, treatment-, and patient-related factors should be considered when selecting therapy. These factors have been reviewed in detail elsewhere. ${ }^{74}$ We briefly highlight some of these factors and how they apply to selection of proteasome inhibitor-based therapy.

The presence of high-risk cytogenetic features is associated with a poor prognosis and there is a need for therapies that can overcome (or partly overcome) this adverse prognosis. Subgroup analyses of the ASPIRE, ENDEAVOR, TOURMALINE-MM1, and CASTOR studies have shown that modern proteasome inhibitor-based combination therapy improves outcomes regardless of cytogenetic risk status, including in patients with high-risk cytogenetics. ${ }^{75-78}$ Safety and tolerability should also be considered when selecting therapy. As peripheral neuropathy is associated with bortezomib, regimens with other proteasome inhibitors (ie, carfilzomib or ixazomib) may be preferred in patients for whom this toxicity is a concern. Similarly, the potential for cardiac toxicity should be considered when evaluating carfilzomibbased therapy. ${ }^{79}$ Safety and efficacy should be considered together and the overall benefit-risk profile assessed. Another factor to consider is convenience. For patients who cannot easily travel to the clinic, an oral proteasome inhibitor such as ixazomib may be preferred. Once-weekly administrations of carfilzomib and bortezomib have been evaluated, ${ }^{44,80}$ and these may be more convenient than the currently approved twice-weekly administrations.

As survival times have improved for patients with multiple myeloma, quality of life considerations and patient-reported outcomes have gained in importance when selecting therapy. However, until recently, there were limited data regarding effect of proteasome inhibitor-based therapies on quality of life in 
501

502

503

504

505

506

507

508

509

510

511

512

513

514

515

516

517

518

519

520

521

522

523

524

patients with relapsed/refractory multiple myeloma. ${ }^{81} \mathrm{~A}$ prespecified exploratory analysis of the phase 3 APEX trial showed that patients with relapsed multiple myeloma who received bortezomib had better health-related quality of life (HRQoL) than those who received dexamethasone. ${ }^{82}$ Recent data from the ENDEAVOR, ASPIRE, and TOURMALINE-MM1 studies have provided important additional information regarding the effects of next-generation proteasome inhibitors on quality of life. A prespecified analysis of the ENDEAVOR study showed that treatment with carfilzomib resulted in statistically significant improvements in patient-reported health-related quality of life, fatigue, pain, side effects of treatment, and neurotoxicity compared with bortezomib treatment. ${ }^{83}$ In ASPIRE, the addition of carfilzomib to lenalidomide resulted in a statistically significant and clinically meaningful improvement in healthrelated quality life with no detrimental effect (compared with the control group) on other patientreported outcomes. ${ }^{84}$ The addition of ixazomib to lenalidomide and dexamethasone in the TOURMALINE-MM1 study did not have a statistically significant impact on health-related quality of life. ${ }^{85}$ Overall, these studies show that combination regimens based on next-generation proteasome inhibitors are able to improve (carfilzomib) or maintain (ixazomib) health-related quality of life compared with recent standards of care in relapsed/refractory multiple myeloma.

\section{Conclusion}

Proteasome inhibitor-based regimens are essential components of modern therapy for patients with relapsed/refractory myeloma, with demonstrated activity including in key subgroups such as patients in first relapse and patients with prior proteasome inhibitor exposure. Consistent data from randomized studies show that modern combination regimens incorporating proteasome inhibitors improve clinical outcomes (including OS in some cases) compared with standard of care in patients with relapsed/refractory multiple myeloma. Both doublet and triplet regimens are approved in this disease setting and both are demonstrated to be effective. The only head-to-head study directly comparing 2 proteasome inhibitors in relapsed/refractory multiple myeloma, ENDEAVOR, demonstrated 
improvements in complete responses, PFS, and OS for the carfilzomib-treated patients compared with the bortezomib-treated patients. ASPIRE is the only phase 3 study in relapsed/refractory multiple myeloma to date to demonstrate an improvement in OS with the addition of a proteasome inhibitor. The benefit was most prominent when the carfilzomib, lenalidomide, and dexamethasone combination was used at first relapse, especially in proteasome inhibitor-sensitive patients (after bortezomib-based frontline therapy). Ixazomib, lenalidomide, and dexamethasone is the only approved, all-oral proteasome inhibitor-based regimen and it offers a convenient choice when infusion therapy is not an option. Bortezomib re-treatment can be an option in certain markets with limited access to modern therapies.

There are currently 3 approved proteasome inhibitors, each with their own unique efficacy and safety profiles. Bortezomib is rapidly active and has a defined efficacy and safety profile that is well-understood by clinicians. It will remain a standard of care option in the frontline setting for the foreseeable future. The duration of bortezomib treatment is limited by peripheral neuropathy and development of relapsed/refractory disease. Like bortezomib, carfilzomib is also rapidly active. In our experience, carfilzomib can be administered for an extended period ( 2 to 3 years), especially when given once weekly. It is the proteasome inhibitor of choice at relapse because of its PFS and OS advantage compared with other therapies (including bortezomib retreatment) and its ability to be combined with many other agents. Several different dose densities (once- vs. twice- weekly) and dose intensities (twiceweekly carfilzomib with lenalidomide and dexamethasone: $27 \mathrm{mg} / \mathrm{m}^{2}$, twice-weekly carfilzomib with dexamethasone: $56 \mathrm{mg} / \mathrm{m}^{2}$, once-weekly carfilzomib with dexamethasone: $70 \mathrm{mg} / \mathrm{m}^{2}$ ) of carfilzomib have been evaluated in randomized phase 3 trials, and the various doses and schedules have the potential to offer greater flexibility in the administration and utility of carfilzomib. In contrast to bortezomib and carfilzomib, ixazomib is an oral drug and thus a convenient option for patients who can come to treatment centers. 
The role of proteasome inhibitors as a class and the 3 currently approved agents will continue to evolve

550

551

552

553

554

555

556

557

558

559

560

561

562

563 as bortezomib becomes generic worldwide, the next-generation proteasome inhibitors move to the frontline, and additional classes of drugs are incorporated in the therapeutic landscape. The costeffectiveness of generic bortezomib will need to be evaluated and it is likely that generic bortezomib will have a prominent role in markets with limited financial resources, although a recent analysis of ENDEAVOR predicted that twice-weekly carfilzomib $56 \mathrm{mg} / \mathrm{m}^{2}$ with dexamethasone would be costeffective versus bortezomib and dexamethasone, even at an $85 \%$ price reduction for bortezomib and dexamethasone.$^{86}$ As an increasing number of studies evaluate frontline carfilzomib- and ixazomibbased regimens, the comparative effectiveness of the various proteasome inhibitor-based, upfront combinations will need to be addressed, as well as the benefit-risk profile in specific patient populations. Real-world evidence from claims data and patient registries will be important in this regard. As novel agents with unique mechanisms of action (eg, venetoclax, selinexor, monoclonal antibodies) are introduced and become established, the scope and potential of proteasome inhibitor-based combinations will continue to expand, allowing effective therapy for heavily pretreated and refractory patients as well as tailored combination therapies for distinct patient subgroups.

There are several key knowledge gaps that remain regarding the role of proteasome inhibitors. Compared with the relapsed/refractory setting, phase 3 data in the upfront setting for carfilzomib and ixazomib are limited. In addition, the evaluation of the best partners for proteasome inhibitors is still an active area of study, and in the context of immunomodulation, there remains a question of whether proteasome inhibitors should be combined with immunomodulatory drugs, monoclonal antibodies, or both. To address an aspect of this question, a randomized phase 2 study (NCT02874742) is evaluating the addition of daratumumab to the triplet of bortezomib, lenalidomide, and dexamethasone in patients with newly diagnosed multiple myeloma. Several single-arm trials are also investigating carfilzomib and dexamethasone in combination with daratumumab or lenalidomide plus daratumumab and are already 
demonstrating positive results. ${ }^{87}$ Beyond optimal combinations, there is no uniform standard of care or data from randomized trials regarding how proteasome-based combination therapies should be sequenced. This will become increasingly important as carfilzomib and ixazomib move to the frontline and questions arise as to which proteasome inhibitor to use upfront, which to reserve for later lines, and the efficacy of bortezomib salvage therapy after frontline carfilzomib or ixazomib. Overall, several studies have found that switching to a different proteasome inhibitor or retreatment with the same proteasome inhibitor can be effective strategies for patients progressing after prior proteasome inhibitor exposure..$^{29,32,64,65,88,89}$ Regarding specific sequences, a single-center, retrospective study found that treatment with frontline carfilzomib-based therapy followed by bortezomib-based therapy $(n=15)$ resulted in higher response rates and deeper responses than the reverse sequence of bortezomib-based therapy followed by carfilzomib-based therapy $(n=39)$; however, larger prospective studies are warranted. ${ }^{90}$ Data from ENDEAVOR suggest it is more effective to switch to carfilzomib rather than retreat with bortezomib. Regarding retreatment with carfilzomib, 1 phase 2 study $(n=13)$ found that retreatment with carfilzomib $56 \mathrm{mg} / \mathrm{m}^{2}$ recaptured responses in patients who were refractory to carfilzomib at a lower dose $\left(27 \mathrm{mg} / \mathrm{m}^{2}\right) .{ }^{91}$ Other knowledge gaps include the value of minimal residual disease testing to assess response to proteasome inhibitor-based therapy, development of alternative oral proteasome inhibitors, and effects of proteasome inhibitors on immune fitness and immunomodulation.

The current treatment paradigm in multiple myeloma emphasizes use of potent combination therapy capable of producing deep and sustained responses. Modern proteasome inhibitor-based regimens are highly effective and are an important option for treating patients with relapsed/refractory disease.

\section{Acknowledgements}


595 Medical writing assistance was provided by BlueMomentum, an Ashfield company, part of UDG 596 Healthcare plc, and funded by Amgen Inc.

597

598 Funding sources

599 Funding: This work was supported by Amgen Inc.

600

601 
602

603 1. Kumar SK, Rajkumar V, Kyle RA, et al. Multiple myeloma. Nat Rev Dis Primers. 2017;3:17046.

604 2. Siegel RL, Miller KD, Jemal A. Cancer Statistics, 2017. CA Cancer J Clin. 2017;67:7-30.

605

606

607

608

\section{References}

3. Ferlay J, Soerjomataram I, Dikshit R, et al. Cancer incidence and mortality worldwide: sources, methods and major patterns in GLOBOCAN 2012. Int J Cancer. 2015;136:E359-E386.

4. Dimopoulos MA, Richardson PG, Moreau P, Anderson KC. Current treatment landscape for relapsed and/or refractory multiple myeloma. Nat Rev Clin Oncol. 2015;12:42-54.

5. Song X, Cong Z, Wilson K. Real-world treatment patterns, comorbidities, and disease-related complications in patients with multiple myeloma in the United States. Curr Med Res Opin. 2016;32:95-103.

6. Kumar SK, Dispenzieri A, Lacy MQ, et al. Continued improvement in survival in multiple myeloma: changes in early mortality and outcomes in older patients. Leukemia. 2014;28:1122-1128.

7. Kumar SK, Rajkumar SV, Dispenzieri A, et al. Improved survival in multiple myeloma and the impact of novel therapies. Blood. 2008;111:2516-2520.

8. Costa L, Brill IK, Omel J, Godby K, Kumar SK, Brown EE. Recent trends in multiple myeloma incidence and survival by age, race, and ethnicity in the United States. Blood Advances. $2017 ; 1: 282-287$.

9. Arrigo AP, Tanaka K, Goldberg AL, Welch WJ. Identity of the $19 \mathrm{~S}$ 'prosome' particle with the large multifunctional protease complex of mammalian cells (the proteasome). Nature. 1988;331:192194.

10. Falkenburg PE, Haass C, Kloetzel PM, et al. Drosophila small cytoplasmic 19 S ribonucleoprotein is homologous to the rat multicatalytic proteinase. Nature. 1988;331:190-192.

11. Harris JR. Release of a macromolecular protein component from human erythrocyte ghosts. Biochim Biophys Acta. 1968;150:534-537. 
626

627

628

629

630

631

632

633

634

635

636

637

638

639

640

641

642

643

644

645

646

647

648

12. Voges D, Zwickl P, Baumeister W. The 26 S proteasome: a molecular machine designed for controlled proteolysis. Annu Rev Biochem. 1999;68:1015-1168.

13. Muz B, Ghazarian RN, Ou M, Luderer MJ, Kusdono HD, Azab AK. Spotlight on ixazomib: potential in the treatment of multiple myeloma. Drug Des Devel Ther. 2016;10:217-226.

14. Landgren O, Iskander K. Modern multiple myeloma therapy: deep, sustained treatment response and good clinical outcomes. J Intern Med. 2017;281:365-382.

15. Kumar S, Paiva B, Anderson KC, et al. International Myeloma Working Group consensus criteria for response and minimal residual disease assessment in multiple myeloma. Lancet Oncol. 2016;17:e328-e346.

16. van de Velde $\mathrm{H}$, Londhe $\mathrm{A}$, Ataman $\mathrm{O}$, et al. Association between complete response and outcomes in transplant-eligible myeloma patients in the era of novel agents. Eur J Haematol. 2017;98:269-279.

17. National Comprehensive Cancer Network (NCCN). NCCN Clinical Practice Guidelines in Oncology. Multiple Myeloma Version 3.2018. https://www.nccn.org/professionals/physician_gls/pdf/myeloma.pdf. Accessed 4 June 2018.

18. Durie BG, Hoering A, Abidi $\mathrm{MH}$, et al. Bortezomib with lenalidomide and dexamethasone versus lenalidomide and dexamethasone alone in patients with newly diagnosed myeloma without intent for immediate autologous stem-cell transplant (SWOG S0777): a randomised, open-label, phase 3 trial. Lancet. 2017;389:519-527.

19. Li S, Natwick T, Yusuf A, Vidito IS, Mezzi K, Werther W. Treatment sequencing patterns in Medicare-enrolled patients with multiple myeloma. Blood. 2016;128:2120.

20. Stewart AK, Rajkumar SV, Dimopoulos MA, et al. Carfilzomib, lenalidomide, and dexamethasone for relapsed multiple myeloma. N Engl J Med. 2015;372:142-152. 
649

650

651

652

653

654

655

656

657

658

659

660

661

662

663

664

665

666

667

668

669

670

671

672

21. Manasanch EE, Korde N, Zingone A, et al. The proteasome: mechanisms of biology and markers of activity and response to treatment in multiple myeloma. Leuk Lymphoma. 2014;55:1707-1714.

22. Cavo M. Proteasome inhibitor bortezomib for the treatment of multiple myeloma. Leukemia. 2006;20:1341-1352.

23. Neefjes J, Groothuis TA, Dantuma NP. [The 2004 Nobel Prize in Chemistry for the discovery of ubiquitin-mediated protein degradation]. Ned Tijdschr Geneeskd. 2004;148:2579-2582.

24. Arastu-Kapur S, Anderl JL, Kraus M, et al. Nonproteasomal targets of the proteasome inhibitors bortezomib and carfilzomib: a link to clinical adverse events. Clin Cancer Res. 2011;17:2734-2743.

25. Ludwig $\mathrm{H}$, Spencer A, Kovacsovics $\mathrm{T}$, et al. Comparison of proteasome inhibition activity between carfilzomib and bortezomib in the phase 3 Endeavor study. Blood. 2017;130:3125.

26. Kupperman E, Lee EC, Cao Y, et al. Evaluation of the proteasome inhibitor MLN9708 in preclinical models of human cancer. Cancer Res. 2010;70:1970-1980.

27. Orlowski RZ, Nagler A, Sonneveld P, et al. Randomized phase III study of pegylated liposomal doxorubicin plus bortezomib compared with bortezomib alone in relapsed or refractory multiple myeloma: combination therapy improves time to progression. J Clin Oncol. 2007;25:3892-3901.

28. Orlowski RZ, Nagler A, Sonneveld P, et al. Final overall survival results of a randomized trial comparing bortezomib plus pegylated liposomal doxorubicin with bortezomib alone in patients with relapsed or refractory multiple myeloma. Cancer. 2016;122:2050-2056.

29. Petrucci MT, Giraldo P, Corradini P, et al. A prospective, international phase 2 study of bortezomib retreatment in patients with relapsed multiple myeloma. Br J Haematol. 2013;160:649-659.

30. San-Miguel JF, Hungria VT, Yoon SS, et al. Panobinostat plus bortezomib and dexamethasone versus placebo plus bortezomib and dexamethasone in patients with relapsed or relapsed and refractory multiple myeloma: a multicentre, randomised, double-blind phase 3 trial. Lancet Oncol. 2014;15:1195-1206. 
673

674

675

676

677

678

679

680

681

682

683

684

685

686

687

688

689

690

691

692

693

694

31. San-Miguel JF, Hungria VTM, Yoon S-S, et al. Overall survival of patients with relapsed multiple myeloma treated with panobinostat or placebo plus bortezomib and dexamethasone (the PANORAMA 1 trial): a randomised, placebo-controlled, phase 3 trial. Lancet Haem. 2016;3:e506e515.

32. Dimopoulos MA, Moreau P, Palumbo A, et al. Carfilzomib and dexamethasone versus bortezomib and dexamethasone for patients with relapsed or refractory multiple myeloma (ENDEAVOR): a randomised, phase 3, open-label, multicentre study. Lancet Oncol. 2016;17:27-38.

33. Palumbo A, Chanan-Khan A, Weisel K, et al. Daratumumab, bortezomib, and dexamethasone for multiple myeloma. N Engl J Med. 2016;375:754-766.

34. Richardson PG, Hungria VT, Yoon SS, et al. Panobinostat plus bortezomib and dexamethasone in previously treated multiple myeloma: outcomes by prior treatment. Blood. 2016;127:713-721.

35. Moreau P, Masszi T, Grzasko N, et al. Oral ixazomib, lenalidomide, and dexamethasone for multiple myeloma. N Engl J Med. 2016;374:1621-1634.

36. Dimopoulos MA, Goldschmidt H, Niesvizky R, et al. Carfilzomib or bortezomib in relapsed or refractory multiple myeloma (ENDEAVOR): an interim overall survival analysis of an open-label, randomised, phase 3 trial. Lancet Oncol. 2017;18:1327-1337.

37. Siegel DS, Dimopoulos MA, Ludwig H, et al. Improvement in overall survival with carfilzomib, lenalidomide, and dexamethasone in patients with relapsed or refractory multiple myeloma. J Clin Oncol. 2018; e-pub ahead of print 17 January 2018; doi: 10.1200/JCO.2017.76.5032.

38. Spencer A, Hungria VTM, Mateos M-V, et al. Daratumumab, bortezomib, and dexamethasone (DVd) versus bortezomib and dexamethasone $(\mathrm{Vd})$ in relapsed or refractory multiple myeloma (RRMM): updated efficacy and safety analysis of Castor. Blood. 2017;130:3145. 
695

696

697

698

699

700

701

702

703

704

705

706

707

708

709

710

711

712

713

714

39. Dimopoulos MA, Orlowski RZ, Facon T, et al. Retrospective matched-pairs analysis of bortezomib plus dexamethasone versus bortezomib monotherapy in relapsed multiple myeloma. Haematologica. 2015;100:100-106.

40. Papadopoulos KP, Siegel DS, Vesole DH, et al. Phase I study of 30-minute infusion of carfilzomib as single agent or in combination with low-dose dexamethasone in patients with relapsed and/or refractory multiple myeloma. J Clin Oncol. 2015;33:732-739.

41. Dimopoulos MA, Kimball AS. Carfilzomib for relapsed or refractory multiple myeloma - Authors' reply. Lancet Oncol. 2018;19:e2.

42. Dimopoulos MA, Stewart AK, Wang M, et al. Carfilzomib, lenalidomide, and dexamethasone vs lenalidomide and dexamethasone in patients with relapsed multiple myeloma: analysis of response and progression-free survival hazard ratio over time. Haematologica. 2016;101:Abstract P275.

43. Center for Drug Evaluation and Research. Ninlaro (ixazomib) medical review. https://www.accessdata.fda.gov/drugsatfda_docs/nda/2015/2084620rig1s000MedR.pdf. Accessed 6 March 2018.

44. Berenson JR, Cartmell A, Bessudo A, et al. CHAMPION-1: a phase $1 / 2$ study of once-weekly carfilzomib and dexamethasone for relapsed or refractory multiple myeloma. Blood. 2016;127:3360-3368.

45. Moreau P, Mateos MV, Berenson JR, et al. Once weekly versus twice weekly carfilzomib dosing in patients with relapsed and refractory multiple myeloma (A.R.R.O.W.): interim analysis results of a randomised, phase 3 study. Lancet Oncol. 2018; e-pub ahead of print 31 May 2018; doi: $10.1016 / \mathrm{S} 1470-2045(18) 30354-1$

46. Kumar SK, LaPlant B, Roy V, et al. Phase 2 trial of ixazomib in patients with relapsed multiple myeloma not refractory to bortezomib. Blood Cancer J. 2015;5:e338. 
47. Kumar SK, Laplant BR, Reeder CB, et al. Randomized phase 2 trial of two different doses of ixazomib in patients with relapsed multiple myeloma not refractory to bortezomib. Blood. $2015 ; 126: 3050$.

48. Hideshima T, Richardson PG, and Anderson KC. Mechanism of action of proteasome inhibitors and deacetylase inhibitors and the biological basis of synergy in multiple myeloma. Mol Cancer Ther. 2011;10:2034-2042.

49. Berdeja JG, Hart LL, Mace JR, et al. Phase I/II study of the combination of panobinostat and carfilzomib in patients with relapsed/refractory multiple myeloma. Haematologica. 2015;100:670-676.

50. Richardson PG, Schlossman RL, Alsina M, et al. PANORAMA 2: panobinostat in combination with bortezomib and dexamethasone in patients with relapsed and bortezomib-refractory myeloma. Blood. 2013;122(14):2331-2337.

51. Richardson PG, Rocafiguera AO, Beksac M, et al. Pomalidomide (POM), bortezomib, and low-dose dexamethasone (PVd) vs bortezomib and low-dose dexamethasone (Vd) in lenalidomide (LEN)exposed patients (pts) with relapsed or refractory multiple myeloma (RRMM): Phase 3 OPTIMISMM trial. J Clin Oncol. 2018;36(15_suppl):8001.

52. Stadtmauer EA, Abonour R, Cohen AD, et al. Phase I/II dose expansion of a multi-center trial of Carfilzomib and pomalidomide with dexamethasone (Car-Pom-d) in patients with relapsed/refractory multiple myeloma. Blood. 2013;122:690.

53. Jakubowiak AJ, Rosenbaum CA, Stephens LAL, et al. Final results of phase (Ph) $1 / 2$ study of carfilzomib, pomalidomide, and dexamethasone (KPd) in patients (Pts) with relapsed/refractory multiple myeloma (RRMM): A Multi-center MMRC study. Haematologica. 2017;102:P680.

54. Voorhees PM, Mulkey F, Hassoun H, et al. Alliance A061202. A phase I/II study of pomalidomide, dexamethasone and ixazomib versus pomalidomide and dexamethasone for patients with 
multiple myeloma refractory to lenalidomide and proteasome inhibitor based therapy: phase I results. Blood. 2015;126:375.

55. Krishnan A, Kapoor P, Palmer JM, et al. Phase I/II trial of the oral regimen ixazomib, pomalidomide, and dexamethasone in relapsed/refractory multiple myeloma. Leukemia. 2017.

56. Jakubowiak A, Offidani M, Pegourie B, et al. Randomized phase 2 study: elotuzumab plus bortezomib/dexamethasone vs bortezomib/dexamethasone for relapsed/refractory MM. Blood. 2016;127:2833-2840.

57. Harousseau JL, Attal M. How I treat first relapse of myeloma. Blood. 2017;130:963-973.

58. Kumar SK, Therneau TM, Gertz MA, et al. Clinical course of patients with relapsed multiple myeloma. Mayo Clin. Proc 2004;79:867-874.

59. Sonneveld P, Broijl A. Treatment of relapsed and refractory multiple myeloma. Haematologica. 2016;101:396-406.

60. Dingli D, Ailawadhi S, Bergsagel PL, et al. Therapy for relapsed multiple myeloma: guidelines from the Mayo stratification for myeloma and risk-adapted therapy. Mayo Clin Proc. 2017;92:578-598.

61. Moreau P, Joshua D, Chng WJ, et al. Impact of prior treatment on patients with relapsed multiple myeloma treated with carfilzomib and dexamethasone vs bortezomib and dexamethasone in the phase 3 ENDEAVOR study. Leukemia. 2017;31:115-122.

62. Weisel KC, Siegel D, San Miguel JF, et al. Overall survival of patients with relapsed multiple myeloma treated with carfilzomib and dexamethasone versus bortezomib and dexamethasone according to prior line of therapy and previous exposure to bortezomib: secondary analysis of the phase 3 Endeavor study. Blood. 2017;130:1850.

63. Mateos M-V, Estell J, Barreto W, et al. Efficacy of daratumumab, bortezomib, and dexamethasone versus bortezomib and dexamethasone in relapsed or refractory myeloma based on prior lines of therapy: updated analysis of Castor. Blood. 2016;128:1150. 
64. Dimopoulos MA, Stewart AK, Masszi T, et al. Carfilzomib-lenalidomide-dexamethasone vs lenalidomide-dexamethasone in relapsed multiple myeloma by previous treatment. Blood Cancer J. $2017 ; 7: \mathrm{e} 554$.

65. Mateos MV, Masszi T, Grzasko N, et al. Impact of prior therapy on the efficacy and safety of oral ixazomib-lenalidomide-dexamethasone vs placebo-lenalidomide-dexamethasone in patients with relapsed/refractory multiple myeloma in TOURMALINE-MM1. Haematologica. 2017;102:17671775.

66. Jagannath S, Roy A, Kish J, et al. Real-world treatment patterns and associated progression-free survival in relapsed/refractory multiple myeloma among US community oncology practices. Expert Rev Hematol. 2016;9:707-717.

67. Mateos M-V, Goldschmidt H, San Miguel JF, et al. Relapsed or refractory multiple myeloma patients treated with second-line carfilzomib and categorized by prior exposure to bortezomib: a subgroup analysis of the randomized phase 3 Aspire and Endeavor trials. Blood. 2017;130:1840.

68. Siegel DS, Martin T, Wang M, et al. A phase 2 study of single-agent carfilzomib (PX-171-003-A1) in patients with relapsed and refractory multiple myeloma. Blood. 2012;120(14):2817-2825.

69. Kaufman JL, Zimmerman T, Rosenbaum CA, et al. Phase I study of the combination of carfilzomib and panobinostat for patients with relapsed and refractory myeloma: a Multiple Myeloma Research Consortium (MMRC) clinical trial. Blood. 2014;124(21):32.

70. Shah JJ, Stadtmauer EA, Abonour R, et al. Carfilzomib, pomalidomide, and dexamethasone for relapsed or refractory myeloma. Blood. 2015;126(20):2284-2290.

71. Kuhn DJ, Chen Q, Voorhees PM, et al. Potent activity of carfilzomib, a novel, irreversible inhibitor of the ubiquitin-proteasome pathway, against preclinical models of multiple myeloma. Blood. 2007;110(9):3281-3290. 
72. Chauhan D, Tian Z, Zhou B, et al. In vitro and in vivo selective antitumor activity of a novel orally bioavailable proteasome inhibitor MLN9708 against multiple myeloma cells. Clin Cancer Res. 2011;17(16):5311-5321.

73. Moreau P, Pylypenko H, Grosicki S, et al. Subcutaneous versus intravenous administration of bortezomib in patients with relapsed multiple myeloma: a randomised, phase 3, non-inferiority study. Lancet Oncol. 2011;12:431-440.

74. Nooka AK, Kastritis E, Dimopoulos MA, Lonial S. Treatment options for relapsed and refractory multiple myeloma. Blood. 2015;125:3085-3099.

75. Avet-Loiseau H, Bahlis NJ, Chng WJ, et al. Ixazomib significantly prolongs progression-free survival in high-risk relapsed/refractory myeloma patients. Blood. 2017;130:2610-2618.

76. Avet-Loiseau H, Fonseca R, Siegel D, et al. Carfilzomib significantly improves the progression-free survival of high-risk patients in multiple myeloma. Blood. 2016;128:1174-1180.

77. Chng WJ, Goldschmidt H, Dimopoulos MA, et al. Carfilzomib-dexamethasone vs bortezomibdexamethasone in relapsed or refractory multiple myeloma by cytogenetic risk in the phase 3 study ENDEAVOR. Leukemia. 2017;31:1368-1374.

78. Weisel KC, Miguel JS, Cook G, et al. Efficacy of daratumumab in combination with lenalidomide plus dexamethasone (DRd) or bortezomib plus dexamethasone (DVd) in relapsed or refractory multiple myeloma (RRMM) based on cytogenetic risk status. J Clin Oncol. 2017;35:8006.

79. Waxman AJ, Clasen S, Hwang WT, et al. Carfilzomib-associated cardiovascular adverse events: a systematic review and meta-analysis. JAMA Oncol. 2017:e174519.

80. Bringhen S, Larocca A, Rossi D, et al. Efficacy and safety of once-weekly bortezomib in multiple myeloma patients. Blood. 2010;116:4745-4753. 
81. Sparano F, Cavo M, Niscola P, Caravita T, Efficace F. Patient-reported outcomes in relapsed/refractory multiple myeloma: a systematic review. Support Care Cancer. 2018;26(7):2075-2090.

82. Lee SJ, Richardson PG, Sonneveld P, et al. Bortezomib is associated with better health-related quality of life than high-dose dexamethasone in patients with relapsed multiple myeloma: results from the APEX study. Br J Haematol. 2008;143:511-519.

83. Ludwig $H$, Moreau $P$, Dimopoulos MA, et al. Health related quality of life results from the openlabel, randomized, phase III Endeavor trial evaluating carfilzomib and dexamethasone versus bortezomib and dexamethasone in patients with relapsed or refractory multiple myeloma. Blood. 2016;128:3309.

84. Stewart AK, Dimopoulos MA, Masszi T, et al. Health-related quality-of-life results from the openlabel, randomized, phase III ASPIRE trial evaluating carfilzomib, lenalidomide, and dexamethasone versus lenalidomide and dexamethasone in patients with relapsed multiple myeloma. J Clin Oncol. 2016;34:3921-3930.

85. Leleu X, Masszi T, Bahlis NJ, et al. Patient-reported health-related quality of life from the phase III TOURMALINE-MM1 study of ixazomib-lenalidomide-dexamethasone versus placebo-lenalidomidedexamethasone in relapsed/refractory multiple myeloma. Am J Hematol. 2018; E-pub ahead of print 4 May 2018; doi: 10.1002/ajh.25134

86. Jakubowiak AJ, Houisse I, Májer I, et al. Cost-effectiveness of carfilzomib plus dexamethasone compared with bortezomib plus dexamethasone for patients with relapsed or refractory multiple myeloma in the United States. Expert Rev Hematol. 2017;10(12):1107-1119.

87. Chari A, Martinez-Lopez J, Mateos MV, et al. Daratumumab (DARA) in combination with carfilzomib and dexamethasone (D-Kd) in lenalidomide (Len)-refractory patients (Pts) with 

2018;36(suppl):8002.

88. Berenson JR, Hilger JD, Yellin O, et al. Replacement of bortezomib with carfilzomib for multiple myeloma patients progressing from bortezomib combination therapy. Leukemia. $2014 ; 28(7): 1529-1536$.

89. Berenson A, Vardanyan S, David M, et al. Outcomes of multiple myeloma patients receiving bortezomib, lenalidomide, and carfilzomib. Ann Hematol. 2017;96(3):449-459.

90. Diamond B, Rossi AC, Pearse RN, et al. Sequencing of proteasome inhibitors in patients with multiple myeloma. Blood. 2016;128(22):4522.

91. Chari A, Cho HJ, Parekh S, et al. Recapturing disease response: a phase II study of high dose carfilzomib in patients with relapsed or refractory multiple myeloma who have progressed on standard dose carfilzomib. Blood. 2015;126(23):3051. 
Table 1. Baseline Characteristics From Pivotal Trials in RRMM

\begin{tabular}{|c|c|c|c|c|c|c|}
\hline $\begin{array}{l}\text { Study Name } \\
\text { (reference) }\end{array}$ & Patient Population & $\begin{array}{l}\text { Treatment } \\
\text { Group (n) }\end{array}$ & $\begin{array}{c}\text { Median (range) } \\
\text { Age, years }\end{array}$ & ECOG PS, \% & $\begin{array}{c}\text { Cytogenetic Risk } \\
\text { Status, }{ }^{a} \%\end{array}$ & $\begin{array}{c}\text { Median (range) Number } \\
\text { of Prior Regimens, } n\end{array}$ \\
\hline \multicolumn{7}{|l|}{ 2-drug regimens } \\
\hline $\begin{array}{l}\text { DOXIL-MMY- } \\
3001^{27,28}\end{array}$ & RRMM, V-naive & V+PLD (324) & $61(28-85)$ & $\begin{array}{l}0: 43 ; \\
1: 57\end{array}$ & $\begin{array}{l}\text { Had cytogenetic } \\
\text { abnormality: } 43 ; \\
\text { Did not have } \\
\text { cytogenetic } \\
\text { abnormality: } 57\end{array}$ & $\begin{array}{c}\text { NR (34\% and } 66 \% \text { had } 1 \\
\text { or } \geq 2 \text { prior therapies, } \\
\text { respectively) }\end{array}$ \\
\hline RETRIEVE 29 & $\begin{array}{l}\text { Patients with MM who } \\
\text { had relapsed after } \\
\text { achieving } \geq \text { PR with } \\
\text { initial V-based } \\
\text { therapy }\end{array}$ & $\begin{array}{c}\mathrm{V} \pm \mathrm{DEX} \text { re- } \\
\text { treatment } \\
(130)\end{array}$ & $67(38-86)$ & $\mathrm{NR}$ & NR & $2(1-7)$ \\
\hline PANORAMA $1^{30,31}$ & $\begin{array}{l}\text { Relapsed or relapsed } \\
\text { and refractory MM, 1- } \\
3 \text { previous treatments }\end{array}$ & $\operatorname{Vd}(381)$ & 63 (IQR, 56-68) & $\begin{array}{l}0: 43 \\
1: 49 \\
2: 8\end{array}$ & NR & $\begin{array}{c}\text { NR }(52 \%, 28 \% \text {, and } 20 \% \\
\text { had } 1,2 \text {, or } 3 \text { prior lines, } \\
\text { respectively) }\end{array}$ \\
\hline ENDEAVOR $^{32}$ & $\begin{array}{c}\text { RRMM, 1-3 previous } \\
\text { treatments }\end{array}$ & $\begin{array}{l}\text { Kd56 (464) } \\
\text { Treatment }\end{array}$ & 65 (35-89) & $\begin{array}{l}\text { 0: 48; } \\
1: 45\end{array}$ & $\begin{array}{c}\text { High: 25; } \\
\text { Standard: } 75\end{array}$ & $2(\mathrm{IQR}, 1-2)$ \\
\hline
\end{tabular}




\begin{tabular}{|c|c|c|c|c|c|c|}
\hline & & until PD & & $2: 7$ & & \\
\hline & $\begin{array}{c}\text { RRMM, 1-3 previous } \\
\text { treatments }\end{array}$ & $\begin{array}{c}\text { Vd (465) } \\
\text { Treatment } \\
\text { until PD }\end{array}$ & $65(30-88)$ & $\begin{array}{l}0: 50 \\
1: 44 \\
2: 6\end{array}$ & $\begin{array}{c}\text { High: 28; } \\
\text { Standard: } 72\end{array}$ & $2(I Q R, 1-2)$ \\
\hline CASTOR $^{33}$ & $\begin{array}{c}\text { Relapsed or relapsed } \\
\text { and refractory MM, } \geq 1 \\
\text { previous treatment }\end{array}$ & $\begin{array}{l}\text { Vd (247) } \\
\text { Up to } 8 \text { cycles } \\
\text { of treatment [6 } \\
\text { months] }\end{array}$ & $64(33-85)$ & NR & $\begin{array}{c}\text { High: } 21 ; \\
\text { Standard: } 79\end{array}$ & $2(1-10)$ \\
\hline 3-drug regimens & & & & & & \\
\hline PANORAMA1 ${ }^{30,31,34}$ & $\begin{array}{l}\text { Relapsed or relapsed } \\
\text { and refractory MM, 1- } \\
3 \text { previous treatments }\end{array}$ & PanVd (387) & 63 (IQR, 56-69) & $\begin{array}{l}0: 45 \\
1: 49 \\
2: 5\end{array}$ & NR & $\begin{array}{l}\text { NR }(51 \%, 32 \% \text {, and } 17 \% \\
\text { had } 1,2 \text {, or } 3 \text { prior lines, } \\
\text { respectively) }\end{array}$ \\
\hline ASPIRE $^{20}$ & $\begin{array}{c}\text { RRMM, 1-3 previous } \\
\text { treatments }\end{array}$ & KRd (396) & $64(38-87)$ & $\begin{array}{c}0 \text { or } 1: 90 \\
2: 10\end{array}$ & $\begin{array}{c}\text { High: } 25 \\
\text { Standard: } 75\end{array}$ & $2(1-3)$ \\
\hline $\begin{array}{l}\text { TOURMALINE- } \\
\text { MM1 }^{35}\end{array}$ & $\begin{array}{l}\text { Relapsed, refractory, } \\
\text { or relapsed and } \\
\text { refractory MM, 1-3 } \\
\text { previous treatments }\end{array}$ & IRd (360) & $66(38-91)$ & $\begin{array}{l}0: 51 \\
1: 44 \\
2: 5\end{array}$ & $\begin{array}{c}\text { High: } 27 ; \\
\text { Standard: } 73\end{array}$ & $\begin{array}{l}\text { NR }(62 \%, 27 \% \text {, and } 11 \% \\
\text { had } 1,2 \text {, or } 3 \text { prior } \\
\text { therapies, respectively) }\end{array}$ \\
\hline CASTOR $^{33}$ & $\begin{array}{l}\text { Relapsed or relapsed } \\
\text { and refractory } \mathrm{MM}, \geq 1\end{array}$ & DVd (251) & $64(30-88)$ & NR & $\begin{array}{c}\text { High: 23; } \\
\text { Standard: } 77\end{array}$ & $2(1-9)$ \\
\hline
\end{tabular}


previous treatment

aPercentages are based on the number of patients with known cytogenetics information.

Abbreviations: DEX=dexamethasone; DVd=daratumumab, bortezomib, and dexamethasone; ECOG PS=Eastern Cooperative Oncology Group performance status; IQR=

interquartile range; IRd=ixazomib, lenalidomide, and dexamethasone; $K d 56=$ carfilzomib $\left(56 \mathrm{mg} / \mathrm{m}^{2}\right)$ and dexamethasone; KRd=carfilzomib, lenalidomide, and dexamethasone;

$\mathrm{MM}=$ multiple myeloma; $\mathrm{NR}=$ not reported; PanVd=panobinostat, bortezomib and dexamethasone; $\mathrm{PD}=$ progressive disease; $\mathrm{Pl}=$ proteasome inhibitor; $\mathrm{PLD}=$ pegylated liposomal

doxorubicin; PR=partial response; Rd=lenalidomide and dexamethasone; RRMM=relapsed or refractory multiple myeloma; $\mathrm{V}=$ bortezomib; $\mathrm{Vd}=$ bortezomib and dexamethasone.

849 
Table 2. Activity of Approved PI-Based Combination Therapies in RRMMa

\begin{tabular}{|c|c|c|c|c|c|c|c|}
\hline Study Name (reference) & Patient Population & $\begin{array}{l}\text { Treatment } \\
\text { Group (n) }\end{array}$ & ORR ( $\geq \mathrm{CR}), \%$ & $\begin{array}{c}\text { Median } \\
\text { PFS, } \\
\text { months }\end{array}$ & PFS Rates & $\begin{array}{c}\text { Median } \\
\text { OS, } \\
\text { months }\end{array}$ & OS Rates \\
\hline \multicolumn{8}{|l|}{ 2-drug regimens } \\
\hline DOXIL-MMY-300127,28 & RRMM, V-naive & V+PLD (324) & $44\left(4^{b}\right)$ & 9.0 & $\begin{array}{c}\text { 1-year: } 26 \% \text {; } \\
\text { 2-year: NR }\end{array}$ & 33.0 & $\begin{array}{l}\text { 1-year: } 81 \%^{c} ; \\
\text { 2-year: } 64 \%^{c}\end{array}$ \\
\hline \multirow[t]{2}{*}{ PANORAMA1 ${ }^{30,31,34}$} & $\begin{array}{l}\text { Relapsed or relapsed } \\
\text { and refractory MM, 1- } \\
3 \text { previous treatments }\end{array}$ & $\operatorname{Vd}(381)$ & $55\left(6^{b}\right)$ & 8.1 & $\begin{array}{c}\text { 1-year: } 36 \% \text {; } \\
\text { 2-year: } 8 \%{ }^{c}\end{array}$ & 35.8 & $\begin{array}{l}\text { 1-year: } 81 \% \text {; } \\
\text { 2-year: } 62 \% c\end{array}$ \\
\hline & $\begin{array}{c}\text { Relapsed or relapsed } \\
\text { and refractory MM, } \geq 2 \\
\text { previous regimens } \\
\text { including } \mathrm{V} \text { and an } \\
\text { immunomodulatory } \\
\text { agent }\end{array}$ & $\operatorname{Vd}(74)$ & $\begin{array}{c}39(\geq \mathrm{CR} \text { not } \\
\text { reported })\end{array}$ & 4.7 & $\begin{array}{c}\text { 1-year: } 16 \% \text {; } \\
\text { 2-year: } 5 \%{ }^{c}\end{array}$ & 19.5 & $\begin{array}{l}\text { 1-year: } 67 \% \text {; } \\
\text { 2-year: } 44 \% c\end{array}$ \\
\hline ENDEAVOR $^{32,36}$ & $\begin{array}{c}\text { RRMM, 1-3 previous } \\
\text { treatments }\end{array}$ & $\begin{array}{l}\text { Kd56 (464) } \\
\text { Treatment until }\end{array}$ & $77(13)$ & 18.7 & $\begin{array}{l}\text { 1-year: } 63 \% \text {; } \\
\text { 2-year: } 44 \%^{c}\end{array}$ & 47.6 & $\begin{array}{l}\text { 1-year: } 83 \% \text {; } \\
\text { 2-year: } 70 \% c\end{array}$ \\
\hline
\end{tabular}

PD 


\begin{tabular}{|c|c|c|c|c|c|c|}
\hline RRMM, $1-3$ previous & Vd (465) & $63(6)$ & 9.4 & 1-year: $42 \%$ c; & 40.0 & 1-year: 83\%c; \\
\hline treatments & Treatment until & & & 2 -year: $23 \%^{c}$ & & 2-year: $63 \%^{c}$ \\
\hline
\end{tabular}

PD

\begin{tabular}{|c|c|c|c|c|c|c|c|}
\hline CASTOR $^{33}$ & $\begin{array}{c}\text { Relapsed or relapsed } \\
\text { and refractory } \mathrm{MM}, \geq 1 \\
\text { previous treatment }\end{array}$ & $\begin{array}{l}\text { Vd (247) } \\
\text { Up to } 8 \text { cycles } \\
\text { of treatment [6 } \\
\text { months] }\end{array}$ & $63(9)$ & $7.1^{\mathrm{c}}$ & $\begin{array}{l}\text { 1-year: } 27 \% \\
\text { 2-year: } 5 \% \text { d }\end{array}$ & NR & $\begin{array}{c}\text { 1-year: } 82 \% \text {; } \\
\text { 2-year: NR }\end{array}$ \\
\hline \multicolumn{8}{|l|}{ 3-drug regimens } \\
\hline ASPIRE $^{20,37}$ & $\begin{array}{c}\text { RRMM, 1-3 previous } \\
\text { treatments }\end{array}$ & KRd (396) & $87(32)$ & 26.3 & $\begin{array}{l}\text { 1-year: } 77 \% \text {; } \\
\text { 2-year: } 55 \% c\end{array}$ & 48.3 & $\begin{array}{l}\text { 1-year: } 89 \%^{c} ; \\
\text { 2-year: } 73 \% c\end{array}$ \\
\hline TOURMALINE-MM135 & $\begin{array}{l}\text { Relapsed, refractory, } \\
\text { or relapsed and } \\
\text { refractory MM, 1-3 } \\
\text { previous treatments }\end{array}$ & $\operatorname{IRd}(360)$ & $78(14)$ & 20.6 & $\begin{array}{c}\text { 1-year: } 67 \% \text {; } \\
\text { 2-year: NR }\end{array}$ & NR & NR \\
\hline CASTOR $^{33}$ & $\begin{array}{c}\text { Relapsed or relapsed } \\
\text { and refractory } \mathrm{MM}, \geq 1 \\
\text { previous treatment }\end{array}$ & DVd (251) & $83(19)$ & $16.7^{c}$ & $\begin{array}{l}\text { 1-year: } 61 \% ; \\
\text { 2-year: } 37 \% \text { e }\end{array}$ & NR & $\begin{array}{l}\text { 1-year: } 82 \% \text {; } \\
\text { 2-year: NR }\end{array}$ \\
\hline PANORAMA $1^{30,31,34}$ & $\begin{array}{l}\text { Relapsed or relapsed } \\
\text { and refractory MM, 1- }\end{array}$ & PanVd (387) & $61\left(11^{\mathrm{b}}\right)$ & 12.0 & $\begin{array}{l}\text { 1-year: } 49 \%^{c} \text {; } \\
\text { 2-year: } 21 \%^{c}\end{array}$ & 40.3 & $\begin{array}{l}\text { 1-year: } 80 \%^{c} \text {; } \\
\text { 2-year: } 67 \%^{c}\end{array}$ \\
\hline
\end{tabular}




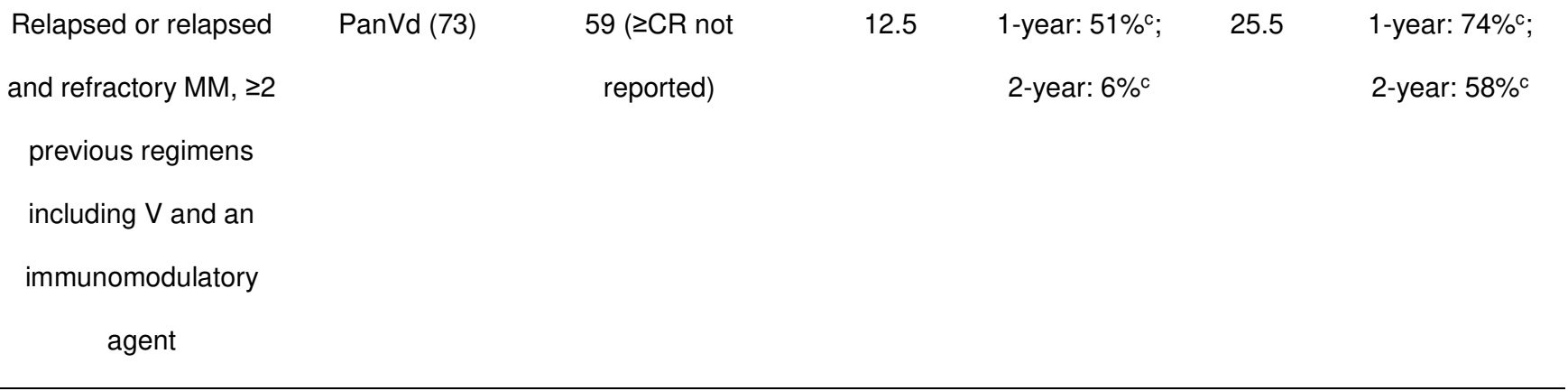

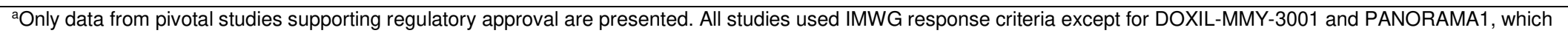

used EBMT criteria. ${ }^{b}$ Rate of CR. ${ }^{~}$ Estimated from Kaplan-Meier curves. ${ }^{d}$ Value is from an updated analysis of CASTOR. ${ }^{38}$ ePresented at the 2017 Annual Meeting of the American Society of Hematology. ${ }^{38}$

Abbreviations: $\mathrm{CR}=$ complete response; $\mathrm{DVd}=$ daratumumab, bortezomib, and dexamethasone; $\mathrm{EBMT}=$ European Group for Blood and Marrow Transplant; IMWG=International

Myeloma Working Group; IRd=ixazomib, lenalidomide, and dexamethasone; Kd56=carfilzomib (56 mg/m²) and dexamethasone; KRd=carfilzomib, lenalidomide, and

dexamethasone; $M M=$ =multiple myeloma; $\mathrm{NR=not} \mathrm{reported,} \mathrm{not} \mathrm{reached,} \mathrm{or} \mathrm{not} \mathrm{estimable;} \mathrm{ORR=overall} \mathrm{response} \mathrm{rate;} \mathrm{OS=overall} \mathrm{survival;} \mathrm{PanVd=panobinostat,} \mathrm{bortezomib} \mathrm{and}$

dexamethasone; PD=progressive disease; PFS=progression-free survival; PI=proteasome inhibitor; PLD=pegylated liposomal doxorubicin; Rd=lenalidomide and dexamethasone;

RRMM=relapsed or refractory multiple myeloma; $V=$ bortezomib; $V d=b o r t e z o m i b$ and dexamethasone.
\end{abstract}




\begin{tabular}{|c|c|c|c|c|c|c|}
\hline Study Name (reference) & Patient Population & $\begin{array}{l}\text { Treatment } \\
\text { Group (n) }\end{array}$ & $\begin{array}{c}\text { ORR ( } \geq \text { CR), } \\
\%\end{array}$ & $\begin{array}{l}\text { Median PFS, } \\
\text { months }\end{array}$ & PFS Rates & $\begin{array}{c}\text { Median OS, } \\
\text { months }\end{array}$ \\
\hline \multicolumn{7}{|l|}{ 2-drug regimens } \\
\hline \multirow[t]{2}{*}{ ENDEAVOR $^{61,62}$} & Relapsed or refractory MM & Kd56 (232) & $82(12)$ & 22.2 & $\begin{array}{l}1 \text {-year: } 71 \%^{\mathrm{a}} \text {; } \\
2 \text {-year: } 43 \%^{\mathrm{a}}\end{array}$ & NR \\
\hline & Relapsed or refractory MM & $\begin{array}{l}\text { Vd [until PD] } \\
\text { (232) }\end{array}$ & $66(8)$ & 10.1 & $\begin{array}{l}\text { 1-year: } 45 \% \text {; } \\
\text { 2-year: NR }\end{array}$ & NR \\
\hline CASTOR $^{38,63}$ & $\begin{array}{l}\text { Relapsed or relapsed and } \\
\text { refractory MM }\end{array}$ & $\begin{array}{l}\text { Vd [6 months] } \\
\text { (113) }\end{array}$ & $74(15)^{b}$ & 7.9 & $\begin{array}{l}\text { 1-year: } 29 \% ; \\
\text { 2-year: } 8 \% \text { b }\end{array}$ & NR \\
\hline \multicolumn{7}{|l|}{ 3-drug regimens } \\
\hline ASPIRE $^{37,64}$ & RRMM & KRd (184) & $87(34)$ & 29.6 & $\begin{array}{l}1 \text {-year: } 80 \%^{\mathrm{a}} \text {; } \\
2 \text {-year: } 58 \%^{\mathrm{a}}\end{array}$ & 47.3 \\
\hline TOURMALINE-MM165 & $\begin{array}{l}\text { Relapsed, refractory, or } \\
\text { relapsed and refractory MM }\end{array}$ & IRd (212) & $77(9)$ & 20.6 & $\begin{array}{l}\text { 1-year: } 65 \% \text {; } \\
\text { 2-year: NR }\end{array}$ & NR \\
\hline CASTOR $^{38,63}$ & $\begin{array}{l}\text { Relapsed or relapsed and } \\
\text { refractory MM }\end{array}$ & DVd (122) & $92(43)^{b}$ & $26.2^{\mathrm{b}}$ & $\begin{array}{l}\text { 1-year: } 78 \% ; \\
\text { 2-year: } 55 \% \text { b }\end{array}$ & NR \\
\hline
\end{tabular}

${ }^{a}$ Estimated from Kaplan-Meier curves. ${ }^{b}$ Presented at the 2017 Annual Meeting of the American Society of Hematology.

Abbreviations: $\mathrm{BTZ}=$ bortezomib; $\mathrm{CR}=$ complete response; DVd=daratumumab, bortezomib, and dexamethasone; IRd=ixazomib, lenalidomide, and dexamethasone;

Kd56=carfilzomib $\left(56 \mathrm{mg} / \mathrm{m}^{2}\right)$ and dexamethasone; KRd=carfilzomib, lenalidomide, and dexamethasone; $\mathrm{MM}=$ =multiple myeloma; $\mathrm{NR}=$ not reported, not reached, not 
estimable; ORR=overall response rate; OS=overall survival; PFS=progression-free survival; PI=proteasome inhibitor; Rd=lenalidomide and dexamethasone;

RRMM=relapsed or refractory multiple myeloma; $\mathrm{Vd}=$ bortezomib and dexamethasone. 
Table 4. Activity of Approved PI-Based Combination Therapies When Used After Prior PI Exposure (Re-Treatment With PIs)

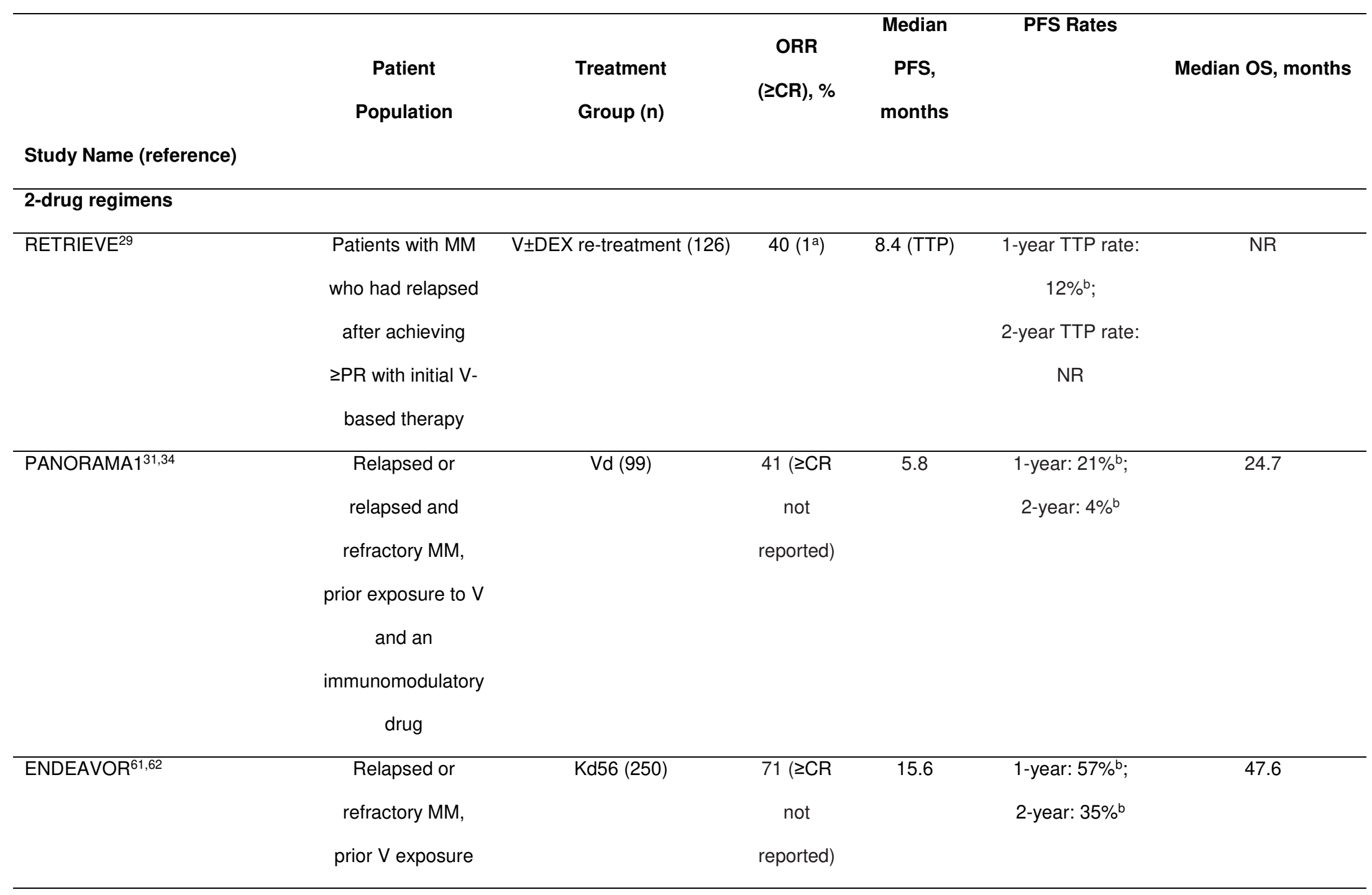




\begin{tabular}{|c|c|c|c|c|c|c|}
\hline & $\begin{array}{l}\text { Relapsed or } \\
\text { refractory MM, } \\
\text { prior V exposure }\end{array}$ & Vd [until PD] (252) & $\begin{array}{c}60 \text { ( } \geq \mathrm{CR} \\
\text { not } \\
\text { reported) }\end{array}$ & 8.1 & $\begin{array}{c}\text { 1-year: 36\% } \\
\text { 2-year: NR }\end{array}$ & 32.8 \\
\hline CASTOR $^{33}$ & $\begin{array}{l}\text { Relapsed or } \\
\text { relapsed and } \\
\text { refractory MM, } \\
\text { prior V exposure }\end{array}$ & Vd [6 months] (164) & NR & 6.7 & NR & NR \\
\hline \multicolumn{7}{|l|}{ 3-drug regimens } \\
\hline PANORAMA $1^{31,34}$ & $\begin{array}{l}\text { Relapsed or } \\
\text { relapsed and } \\
\text { refractory MM, } \\
\text { prior exposure to V } \\
\text { and an } \\
\text { immunomodulatory } \\
\text { drug }\end{array}$ & PanVd (94) & $\begin{array}{c}58.5 \\
(\geq \mathrm{CR} \text { not } \\
\text { reported) }\end{array}$ & 10.6 & $\begin{array}{l}\text { 1-year: 48\%b; } \\
\text { 2-year: } 9 \% \text { b }\end{array}$ & 27.2 \\
\hline ASPIRE $^{64}$ & $\begin{array}{l}\text { RRMM, prior V } \\
\text { exposure }\end{array}$ & $\mathrm{KRd}(261)$ & $86(30)$ & 24.4 & $\begin{array}{l}\text { 1-year: } 75 \%^{\mathrm{b}} ; \\
\text { 2-year: } 52 \%\end{array}$ & NR \\
\hline TOURMALINE-MM165 & $\begin{array}{l}\text { Relapsed, } \\
\text { refractory, or } \\
\text { relapsed and } \\
\text { refractory } \mathrm{MM}, \mathrm{PI}-\end{array}$ & IRd (250) & $77(9)$ & 18.4 & $\begin{array}{c}\text { 1-year: 67\% } \\
\text { 2-year: NR }\end{array}$ & NR \\
\hline
\end{tabular}


exposed

$\begin{array}{llllll}\text { CASTOR }^{33} & \text { Relapsed or } & \text { DVd (162) } & \text { NR } & 12.3 \quad \text { NR } \\ & \text { relapsed and } & & \\ & \text { refractory MM } & & \\ & & & \\ \end{array}$

${ }^{a}$ Results reported for CR. ${ }^{b}$ Estimated from Kaplan-Meier curve.

Abbreviations: $\mathrm{CR}=$ complete response; $\mathrm{DVd}=$ daratumumab, bortezomib, and dexamethasone; $\mathrm{IRd}=\mathrm{ixazomib}$, lenalidomide, and dexamethasone; $\mathrm{Kd} 56=\mathrm{carfilzomib}$ ( $56 \mathrm{mg} / \mathrm{m}^{2}$ )

and dexamethasone; $\mathrm{KRd}=$ carfilzomib, lenalidomide, and dexamethasone; $\mathrm{MM}=$ multiple myeloma; $\mathrm{NR}=\mathrm{not}$ reported; ORR=overall response rate; OS=overall survival;

PFS=progression-free survival; $\mathrm{Pl}=$ proteasome inhibitor; $\mathrm{PanVd}=$ panobinostat, bortezomib and dexamethasone; PD=progressive disease; PLD=pegylated liposomal doxorubicin;

$\mathrm{Rd}=$ lenalidomide and dexamethasone; RRMM=relapsed or refractory multiple myeloma; TTP=time to progression; $\mathrm{V}=$ bortezomib; Vd=bortezomib and dexamethasone. 


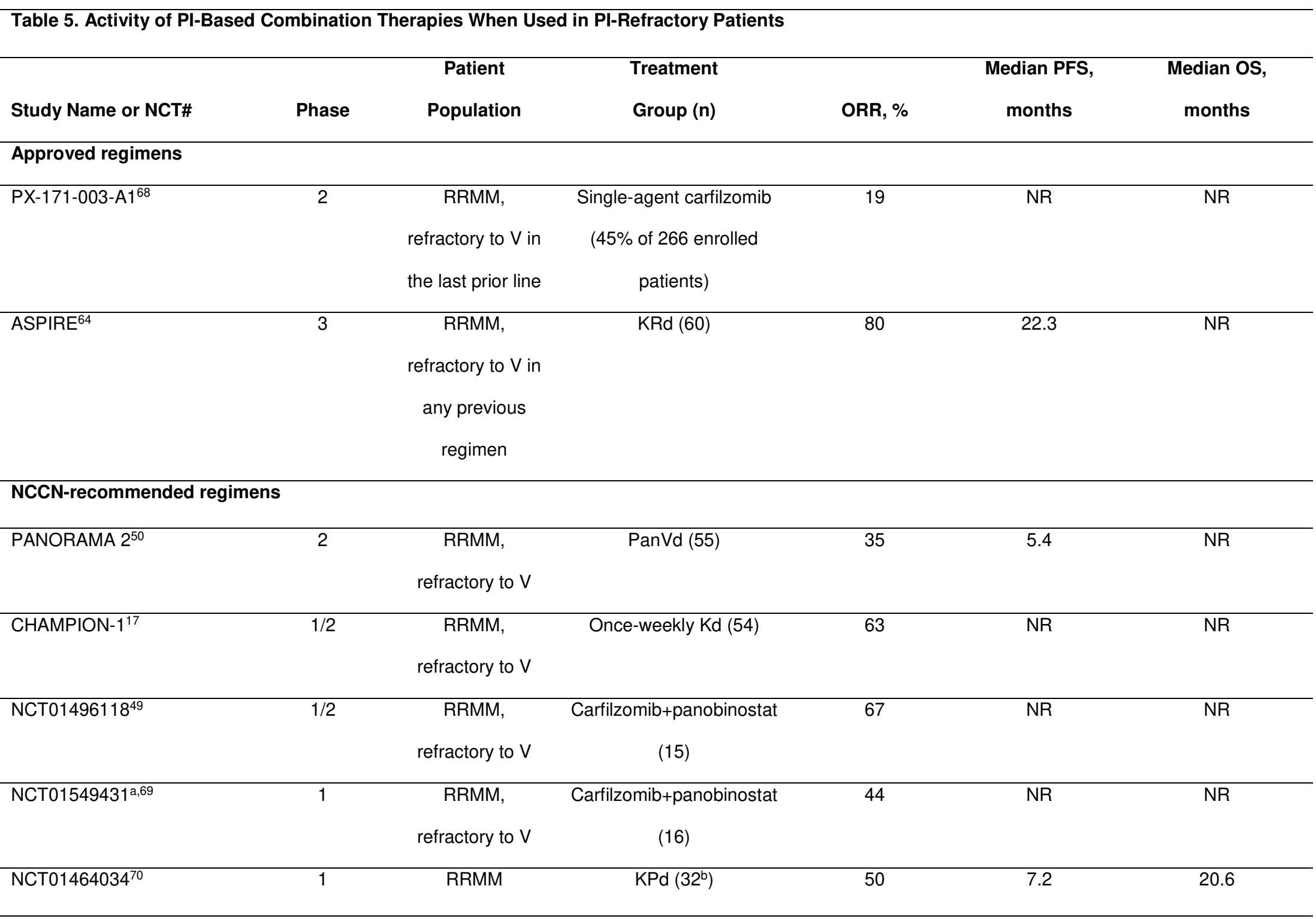




\begin{tabular}{|c|c|c|c|c|c|c|}
\hline NCT02004275 & $1 / 2$ & $\begin{array}{c}\text { MM, refractory to } \\
\text { LEN and a PI }\end{array}$ & $\mathrm{IPd}(17)$ & $62^{c}$ & NR & NR \\
\hline NCT0211946855 & $1 / 2$ & $\begin{array}{c}\text { RRMM, } \\
\text { refractory to LEN } \\
\text { and } V\end{array}$ & $\mathrm{IPd}(14)$ & 29 & NR & NR \\
\hline
\end{tabular}

aPresented at the 2014 ASH Annual Meeting.

b30 of 32 patients were refractory to $\mathrm{V}$.

'ORR was reported for 13 patients who received at least 1 cycle of therapy.

Abbreviations: IPd=ixazomib, pomalidomide, and dexamethasone; KRd=carfilzomib, lenalidomide, and dexamethasone; LEN=lenalidomide; MM=multiple myeloma; $\mathrm{NCCN}$,

National Comprehensive Care Network; NR=not reported or not reached; ORR=overall response rate; OS=overall survival; PFS=progression-free survival; $\mathrm{Pl}=$ proteasome inhibitor; PanVd=panobinostat, bortezomib and dexamethasone; RRMM=relapsed or refractory multiple myeloma; $\mathrm{V=bortezomib;} \mathrm{Vd=bortezomib} \mathrm{and} \mathrm{dexamethasone.}$ 
Table 6. Safety of Approved PI-Based Combination Therapies in RRMM

\begin{tabular}{|c|c|c|c|c|c|c|c|}
\hline \multirow{4}{*}{$\begin{array}{l}\text { Study Name } \\
\text { (reference) }\end{array}$} & \multicolumn{2}{|r|}{ Median } & \multirow[b]{4}{*}{ Any $\mathrm{AE}, \%$} & \multirow[b]{4}{*}{ Grade $\geq 3$ AEs, $\%$} & \multirow[b]{4}{*}{ SAEs, $\%$} & \multirow{4}{*}{$\begin{array}{l}\text { Discontinuations } \\
\text { Due to AEs, (\%) }\end{array}$} & \multirow{4}{*}{$\begin{array}{c}\text { Dose } \\
\text { Reductions } \\
\text { Due to } \\
\text { AEs, (\%) }\end{array}$} \\
\hline & Treatment & Treatment & & & & & \\
\hline & Group, Safety & Duration & & & & & \\
\hline & Population (n) & & & & & & \\
\hline \multicolumn{8}{|l|}{ 2-drug regimens } \\
\hline DOXIL-MMY- & V+PLD (318) & 5 cycles; 105 & 98 & $80^{\mathrm{a}}$ & 36 & $\mathrm{~V}: 30$ & NR \\
\hline $3001^{27}$ & & days & & & & PLD: 36 & \\
\hline PANORAMA1 ${ }^{31}$ & Vd (377) & NR & NR & $82^{a}$ & 42 & 18 & NR \\
\hline \multirow[t]{3}{*}{ ENDEAVOR $^{36}$} & Kd56 (463) & 48.0 weeks & 99 & 81 & 59 & 14 & 32 \\
\hline & Vd [until PD] & 27.0 weeks & 99 & 71 & 40 & 16 & 50 \\
\hline & $(456)$ & & & & & & \\
\hline CASTOR $^{33}$ & Vd [6 months] & Median follow-up & 95 & $62^{\mathrm{a}}$ & NR & 9 & NR \\
\hline & $(237)$ & period was 7.4 & & & & & \\
\hline & & months & & & & & \\
\hline \multicolumn{8}{|l|}{ 3-drug regimens } \\
\hline PANORAMA1 ${ }^{31}$ & PanVd (381) & NR & NR & $96^{a}$ & 60 & 34 & NR \\
\hline ASPIRE $^{37}$ & KRd (392) & 72 weeks for & 98 & 87 & 65 & 20 & $11^{\mathrm{b}}$ \\
\hline
\end{tabular}


carfilzomib

\begin{tabular}{|c|c|c|c|c|c|c|c|}
\hline TOURMALINE- & IRd (361) & 17 cycles & 98 & 74 & 47 & 17 & 56 \\
\hline \multicolumn{8}{|l|}{$M M 1^{35}$} \\
\hline CASTOR $^{33}$ & DVd (243) & $\begin{array}{c}\text { Median follow-up } \\
\text { period was } 7.4 \\
\text { months }\end{array}$ & 99 & $76^{a}$ & NR & 7 & NR \\
\hline
\end{tabular}

${ }^{\mathrm{a} A n y}$ grade 3 or $4 \mathrm{AE} .{ }^{\mathrm{b}}$ Reported in the primary analysis. ${ }^{20}$

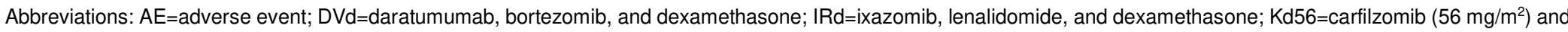
dexamethasone; KRd=carfilzomib, lenalidomide, and dexamethasone; NR=not reported; $\mathrm{Pl}=$ proteasome inhibitor; PanVd=panobinostat, bortezomib and dexamethasone;

$\mathrm{PD}=$ progressive disease; $\mathrm{PLD}=$ pegylated liposomal doxorubicin; $\mathrm{RRMM=relapsed} \mathrm{or} \mathrm{refractory} \mathrm{multiple} \mathrm{myeloma;} \mathrm{SAE}=$ serious $\mathrm{AE} ; \mathrm{V}=$ bortezomib; $\mathrm{Vd}=$ bortezomib and dexamethasone. 